\title{
International Classification of Functioning, Disability and Health in Vocational Rehabilitation: A Scoping Review of the State of the Field
}

\author{
A. H. Momsen ${ }^{1,2,7} \cdot$ C. M. Stapelfeldt ${ }^{1,2} \cdot$ R. Rosbjerg $^{1,2} \cdot$ R. Escorpizo $^{3,4} \cdot$ M. Labriola $^{1,2} \cdot$ M. Bjerrum $^{5,6}$
}

Published online: 5 June 2018

(c) The Author(s) 2018

\begin{abstract}
Purpose The purposes of this study were to provide an outline of the existing literature on operationalization of the International Classification of Functioning, Disability and Health (ICF) within vocational rehabilitation (VR) and to explore the ICF utility within VR. Methods The process was undertaken in five stages according to a framework of scoping review. Screening and extraction of data were done by two independent reviewers, and data was summarized according to content analysis. Results Fifty papers (25 qualitative and 25 quantitative) were included. The operationalization of the ICF was described in four different ways: In total 18 (36\%) papers described use of the ICF for structuring information, $8(15 \%)$ for linking information to ICF, 12 (24\%) for analysis of results, and $12(24 \%)$ for development of a model. In total $15(29 \%)$ papers described VR interventions involving stakeholders, whereas $32(62 \%)$ were reviews. Forty of the papers described all the ICF components. Conclusions The review revealed use of the ICF within the field VR in 50 papers, and in various settings. The ICF framework was most often operationalized for structuring or linking information of functioning. A majority of papers were reviews and involved researchers only, whereas different stakeholders and VR professionals were involved in the interventions. In 40 papers all the ICF components were described, and the ICF was considered a useful tool to inform the VR professionals' assessment of functioning. However, more research within VR is needed to standardize and ease the use of the ICF.
\end{abstract}

Keywords Occupational health services $\cdot$ Rehabilitation $\cdot$ Return to work $\cdot$ Outcome assessment

\section{Background}

Work disability is often associated with personal suffering and loss of income, diminished productivity and increased medical and societal costs and can be addressed through

Electronic supplementary material The online version of this article (https://doi.org/10.1007/s10926-018-9788-4) contains supplementary material, which is available to authorized users.

A. H. Momsen

anne-mette.momsen@rm.dk

1 Section of Clinical Social Medicine and Rehabilitation, Department of Public Health, Aarhus University, 8000 Aarhus, Denmark

2 DEFACTUM - Social \& Health Services and Labour Market, Central Denmark Region, 8000 Aarhus, Denmark

3 Department of Rehabilitation and Movement Science, University of Vermont, Burlington, VT, USA

4 Swiss Paraplegic Research, Nottwil, Switzerland vocational rehabilitation (VR) [1]. The essence of VR is promotion of workers' health in order to enter or return to work (RTW), prevent work disability, and sustain work ability [1-4]. VR professionals have been challenged by different perceptions of health, and researchers argue for a definition of health as a dynamic process of adaptation and self-management [5]. The Organisation for Economic Co-operation and Development (OECD) states that several countries have made efforts to move away from assessing a

5 Danish Centre of Systematic Reviews: A Joanna Briggs Institute Centre of Excellence, Department of Medicine and Technology, University of Aalborg, 9000 Aalborg, Denmark

6 Section of Nursing Science, Department of Public Health, Aarhus University, 8000 Aarhus, Denmark

7 DEFACTUM, Aarhus University Hospital, MarselisborgCentret, P.P. Oerums Gade 11, 8000 Aarhus, Denmark 


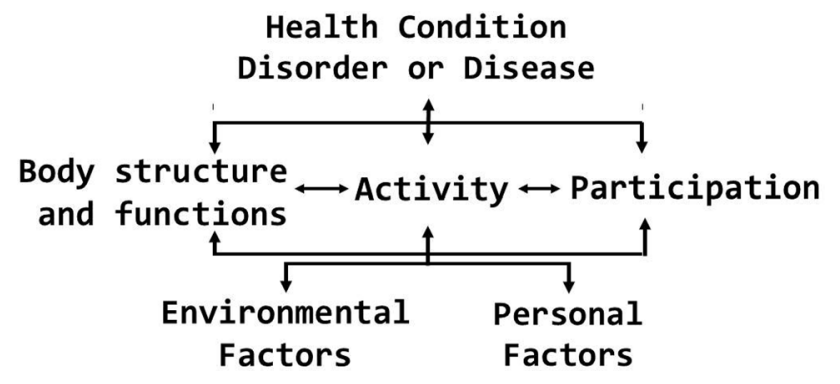

Fig. 1 The internation classification of functioning, disability and health (ICF) framework

person's illness, but instead examining the person's remaining work capacity [6]. The International Classification of Functioning, Disability and Health (ICF) (See Fig. 1) was approved by the World Health Assembly in 2001 [7], and the ICF framework covers a spectrum of body, personal, and societal aspects of human functioning. Thereby, the ICF captures a comprehensive view of disability relevant to VR, and the integration of "functioning" in VR rather than the traditional biomedical approach, which is in line with the efforts stated by OECD [2]. In VR a comprehensive understanding of the aspects influencing patients' functioning is important. Thus, the usefulness of the ICF may be demonstrated in VR [8]. The ICF framework has been proposed to offer opportunities to optimize VR for patients by providing a universal conceptual reference to improve communication between different users, such as health care professionals, researchers, and policy-makers.

There are several definitions of VR, e.g. medical, psychological, social and occupational activities aiming to reestablish sick or injured peoples work capacity and prerequisites for returning or entering the labour market, i.e. to a job or availability for a job, 2009 [9]. In 2011, a broader ICF-based definition of VR was introduced: "A multi-professional evidence-based approach that is provided in different settings, services, and activities to working age individuals with health-related impairments, limitations, or restrictions with work functioning, and whose primary aim is to optimize work participation" [2].

A review showed diversity in the ICF contents of the measures used in the literature, and proposed that the ICF and VR interface should be further examined [10]. Knowing more about how and to what extent the ICF framework is applied and has been utilized is suggested important in order to optimize VR interventions for patients [11] and the inter-professional approach in VR processes [8].

The purposes of this review were to provide an outline of the existing literature and to explore the ICF utility within VR. The primary aim was to examine and map the operationalization of the ICF within VR. The second aim was to examine the different VR professionals' use of the ICF.
Ideally a multi-professional, multimodal approach should be used in VR [12].

Within the WHO a number of ICF core sets have been developed in order to make the ICF more applicable for clinical practice. A third aim was to examine to what extent the components of the ICF framework, the VR core set, and other ICF core sets are used within VR. Core sets are lists of essential ICF-categories in specific health conditions and contexts to describe functioning, e.g. a comprehensive and a brief VR core set were developed and validated for interdisciplinary assessment, documentation, and communication in VR $[13,14]$.

A preliminary search in PROSPERO and PubMed showed no review on the topic, and to our knowledge there are no existing systematic reviews or scoping review on how the ICF is applied within VR.

\section{Methods}

The scoping review was conducted according the methodology conduced in five steps: (1) identifying the research question, (2) identifying relevant studies, (3) study selection, (4) charting the data, and (5) collating, summarizing, and reporting results [15-17].

\section{Identifying the Research Question}

(1) How is the ICF operationalized in empirical papers within VR?

(2) Who are involved and how does the ICF inform the professionals' assessment of functioning in VR?

(3) Which of the ICF components and core sets are considered when functioning is evaluated in VR?

\section{Identifying Relevant Studies}

A three-step search strategy was conducted [16]. Firstly, initial keywords were identified and secondly all identified keywords and index terms were used to build a comprehensive and specific search strategy for each included database: PubMed, Embase, Scopus, CINAHL, PsycINFO, Swemed+, and PEDro. Thirdly, the search strategies were refined: VR and RTW (MeSH term) in PubMed and other terms, e.g. sick leave, work disability were used as keywords [10], and ICIDH was used as ICF was not a MeSH term until 2012 $[18,19]$. The search was performed in collaboration with a research librarian at Aarhus University Library. The search was restricted to papers in English, German, Danish, Swedish, and Norwegian (Online Appendix A). 


\section{Study Selection}

Inclusion criteria: ICF or International Classification of Functioning, Disability and Health mentioned in the title or abstract, ICF used in the field of VR research, peer reviewed original papers and reviews, date of publication from January 2001 to May 2016, abstract available, and study populations of working age adults. There were no limitations regarding including reviews and thereby potential overlap of individual papers included in the reviews. There were no context limitations regarding geography or culture, and papers were eligible from any healthcare setting or research setting (e.g. rehabilitation clinic, in-patient or out-patient clinic, hospital, physicians, primary health care, occupational health services, insurance office, and research departments).

Exclusion criteria: papers only mentioning ICF in the abstract, background or discussion, or only mentioning ICIDH or ICIDH-2, overviews, editorials, comments, theoretical papers, text and opinion papers, theses/dissertations, books, and papers on ICF-Children and Youth.

The process of study selection was reported using the PRISMA [20], and eligible studies were screened independently by two reviewers (AM and MB) followed by consensus discussions. The selection was performed in two groups for qualitative papers (AM and RR) and quantitative papers (AM and CMS), respectively.

\section{Extraction of Data}

Study characteristics were extracted from the included studies using a pilot-tested non-software template. The papers were divided in qualitative and quantitative papers according to qualifications of the review team. Two authors extracted study characteristics independently for qualitative papers (AM and RR) and quantitative papers (AM and CMS), respectively. In case of disagreement, the final decision about characteristics was resolved through discussion. The papers were divided in qualitative and quantitative papers according to the data collection method described.

Study characteristics according to The Joanna Briggs Institute Reviewers' Manual included: first author, publication year, country, setting, study type (intervention yes/no), population, aims, methods, and outcomes [16]. Intervention was defined as "a treatment, whether for preventative or therapeutic reasons, an assessment or diagnostic tool or some other type of service or condition to which a patient might be exposed" [21]. Data from the included studies was coded by two authors (AM and RR; AM and CMS, respectively) using the three research questions.

Regarding the first research question; data was extracted according to the use of the ICF framework as described in the individual papers. Four different ways of operationalization of the ICF were the most typical descriptions used in a subset of the papers included: (a) structuring, (b) linking, (c) analysing, or (d) developing instruments or models, respectively. All the included papers' description were categorised in these. Structuring was considered present, when data or outcomes were categorized, or themes or information from interviews was coded according to the ICF framework. However, in case structuring was followed by other use, data was extracted according to the latter. Linking was considered present, when health information (e.g. from questionnaires or interviews) was coded to specific ICF categories, based on linking rules, e.g. linking items in a questionnaire to categories in a core set $[9,22]$. Analysing was considered present if the paper explicitly described that data were analysed, most commonly after data or information had been structured following the ICF framework. Developing instruments or models based on the ICF framework was the last reported usage.

Regarding the second research question the description of VR professionals (e.g. health professionals) involved were extracted, and a descriptive summary of their use of the ICF in order to inform the assessment of functioning was presented. Regarding the third question; the use of the ICF components (body function, body structures, activity and participation, environmental factors) and the ICF core set(s) was extracted based on the information provided in individual papers.

\section{Collating, Summarizing, and Reporting Results}

A descriptive summary of the charted data was done independently by two authors on all the included papers. The coded data relevant to inform the three review questions were charted from each paper included and categorized according to content analysis [23-25]. Both deductive and inductive analyses were used, as the results were based on the description in the papers, e.g., of the pre-defined ICF components and core sets. The descriptive summary of the main results is presented in tables.

\section{Results}

In total 1343 papers were retrieved from seven databases, of which 702 duplicates were removed; thus, 641 papers were assessed for eligibility (Fig. 2). Sixty-four papers from these were read in full text of which 14 papers were excluded, mainly because the ICF was only mentioned in the introduction or discussion and lack of information on VR. Thus, 50 papers (25 qualitative and 25 quantitative) were included. No additional papers were included.

A descriptive summary of the included study characteristics is shown in Table 1. The ICF referral in papers within VR was found among Western countries, except one paper 


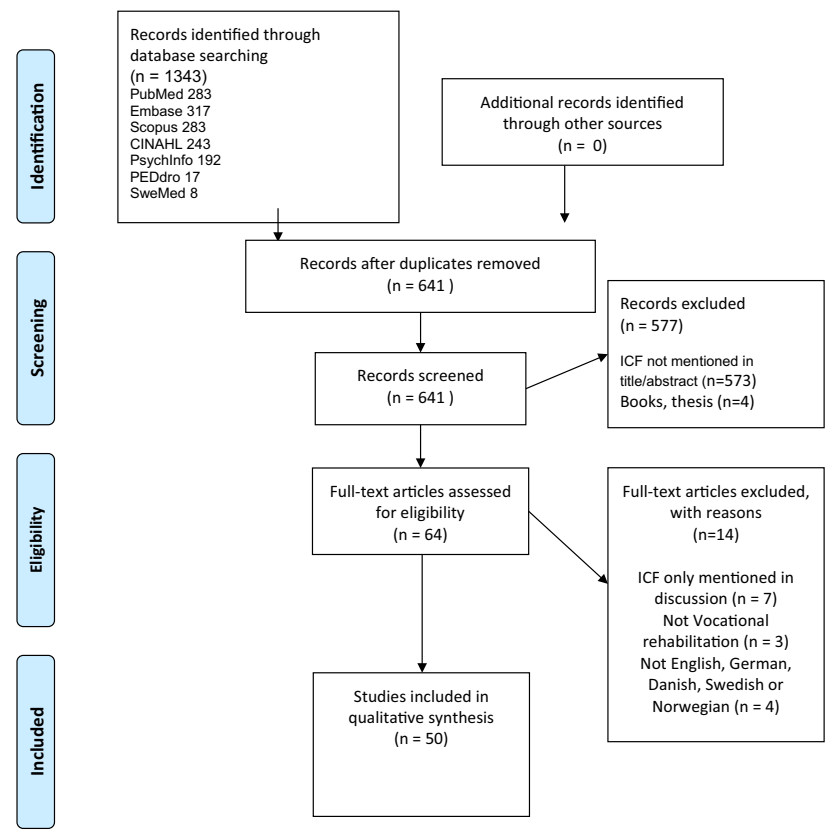

Fig. 2 Flow diagram

from Taiwan. Thus, nine papers were from Switzerland [10, 26-33] four were from the USA [34-37], three from Italy [38-40], two from Germany [41, 42], one from Canada [43], UK [44], Portugal [45], Turkey [46], Slovenia [47], Spain [48], Israel [49], and Taiwan [50]. Five papers were authored by an international [38, 51-54], three were from settings in Sweden [55-57], and three from Norway [58-60].

Although 32 of the papers were reviews, primarily from research settings (e.g. rehabilitation social medicine or physiotherapy departments) in Switzerland and the Netherlands; other VR settings in which the ICF was used were widespread, i.e. hospitals, rehabilitation centres, primary health care centres, and sickness certificate registration offices.

A minority of papers reported interventions within VR; only seven of the qualitative papers [34, 36, 38, 55, 61-63], and eight among the quantitative papers [37, 40-42, 46, 57, $60,64]$. Eleven papers were from health care and research settings in the Netherlands [61-71].

\section{How is the ICF Operationalized in Empirical Papers within VR?}

In total 18 papers (36\%) used the ICF as a framework for structuring of information: twelve of the qualitative papers $[26,27,30,44,61,62,66,68-70,72-74]$, and six of the quantitative papers $[29,37,42,57,64,74]$; e.g. relating information in sickness certificates to the ICF framework [57] (Table 2). As an example, one paper reported that the ICF was used for verifying data on claimants' disabilities by comparing the information provided by the ICF and the bio-psycho model to see the extent of match [61].

In total eight papers (15\%) used the ICF as a framework for linking between ICF categories and e.g. items in questionnaires: three qualitative papers [31, 38, 52], and five quantitative papers [32, 33, 39, 71, 75]; e.g. of Italian legislative procedures to the ICF [39], of factors coded on the second- level ICF classifications [71], of items to the core set and following the linking rules $[32,33,75]$. As an example, one paper aimed at merging an ICF core set for a specific health-related condition (spinal cord injury) to the categories of the VR core set [75]. Another paper identified the concepts within the functional problems which were coded, and linked to ICF categories, or to the categories of the VR core set [38].

The analysis was performed according to the ICF framework in 12 papers (24\%): five qualitative papers [34, 36, 43, 55, 63], e.g. listing of the respondents ' answers followed by frequency analysis according to the relevant ICF domains [55] and seven quantitative papers [28, 40, 46, 49, 50, 56, 58]; e.g. rating and analysing problems regarding work [28], and extraction of phrases from a patients' electronic record that could potentially be interpreted as an ICF category [46]. One of the quantitative papers analysed levels of function and how it correlated with vocational status [49].

The ICF was used as a framework for the development of an instrument or a new model for various aspects within VR in 12 papers (24\%) : five qualitative papers [35, 48, 54, 65, 67]; e.g. a model relating the levels of activity to the ICF [48], and a model explaining work disability by healthrelated problems at work [53]. A paper concluded that the ICF may contribute by informing our thinking of RTW and work maintenance by conceptualizing phase-based RTW outcomes [54]. Seven quantitative papers reported use of the ICF for development [41, 45, 47, 53, 59, 60, 76]; e.g. relating with other questionnaires used in VR [41], and use of the ICF core sets for developing a questionnaire for description of workplace accommodation [60].

\section{Who are Involved and How Does the ICF Inform the Professionals' Assessment of Functioning in VR?}

Four papers described involvement of patients and researchers [34, 55] or patients and health professionals [38, 61]. Two papers described involvement of professionals, employers, and employees as informants [68], medical professionals as evaluators of work disability and researchers [26], respectively. A majority (32) of papers were reviews involving solely the authors (researchers): twenty of the qualitative papers, and eleven of the quantitative papers, respectively. Two papers involved a research team, interviewers and project staff [37], researchers and an adjudicator [56], respectively. Seven papers involved researcher and numerous 


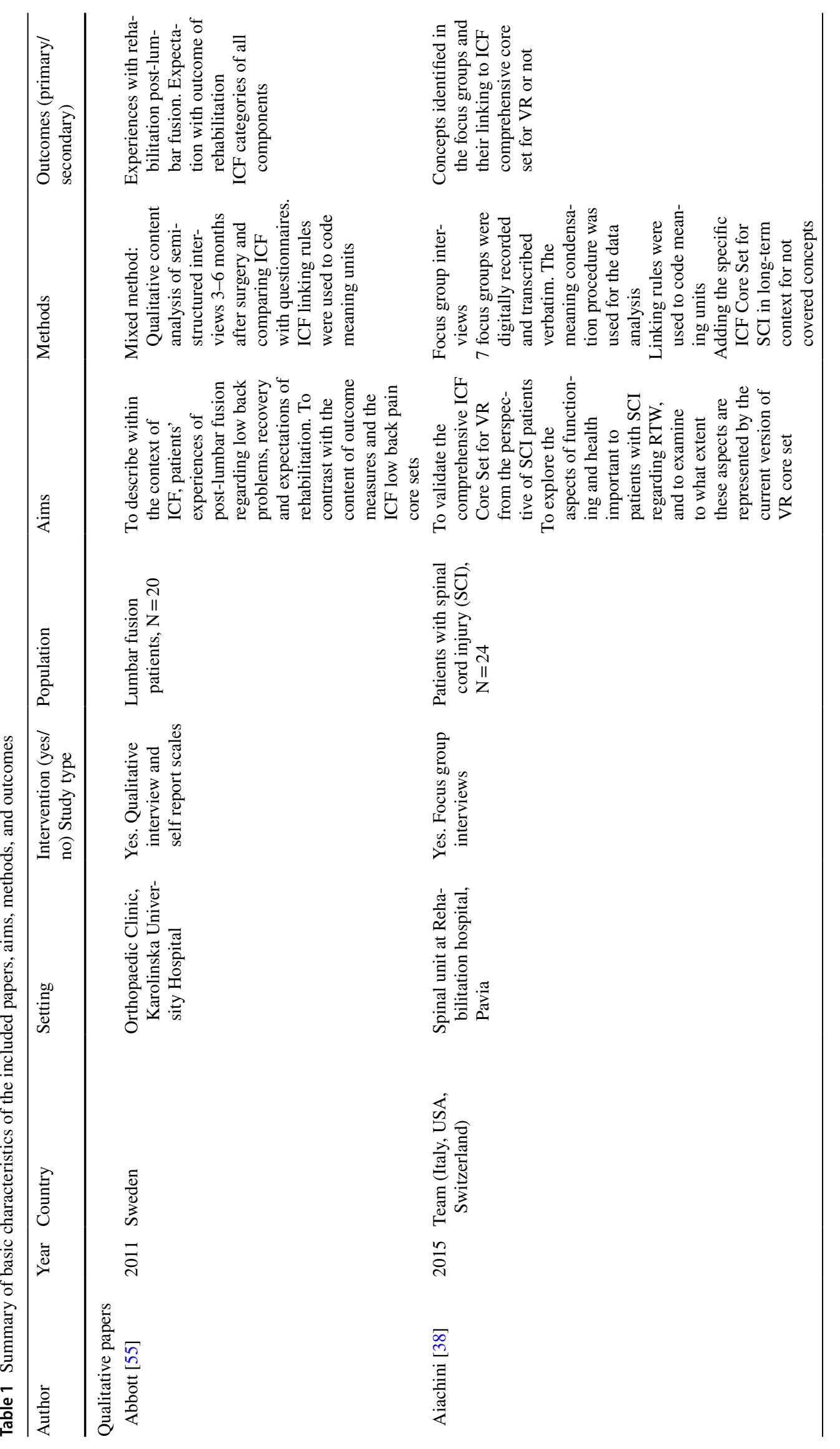




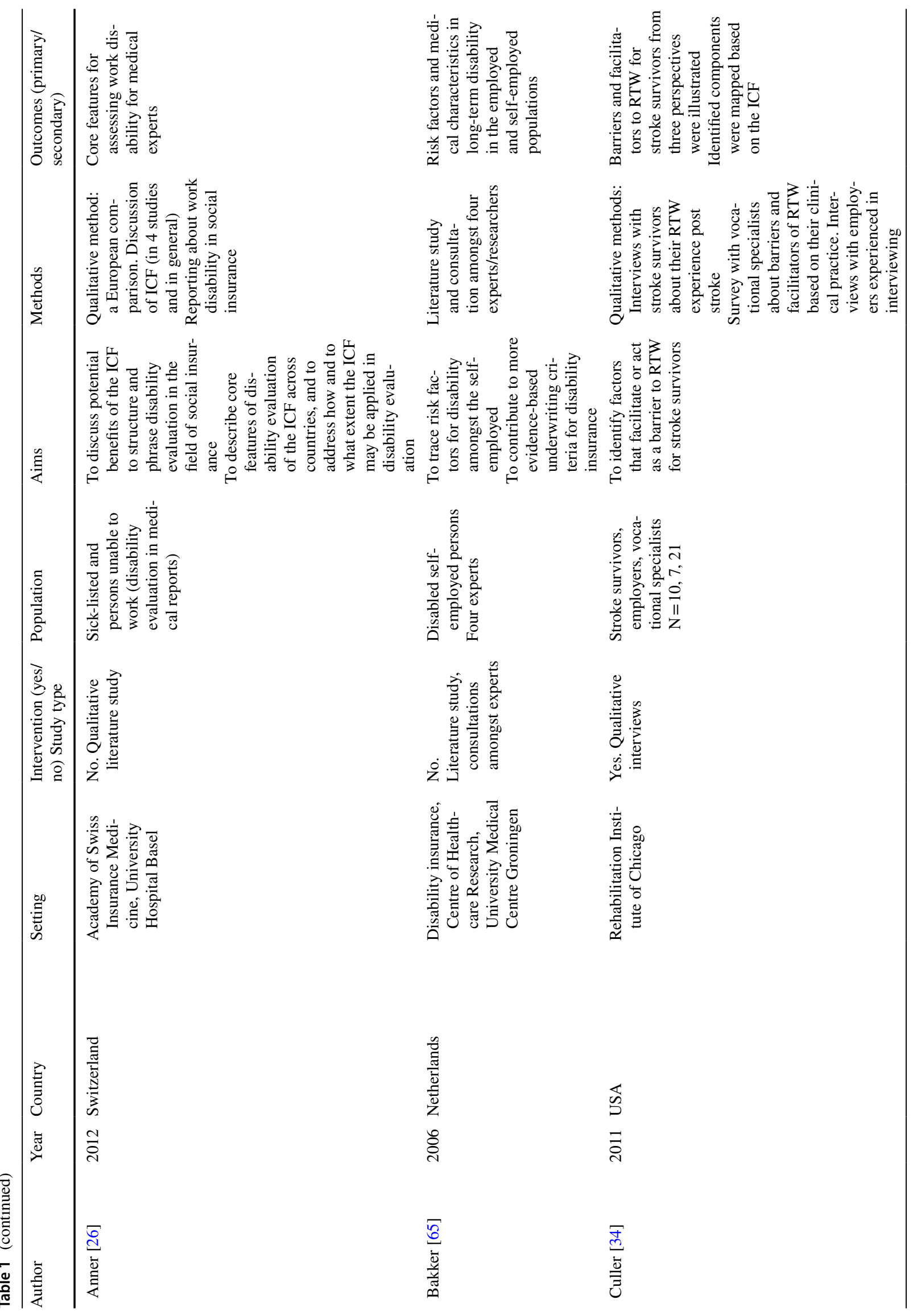




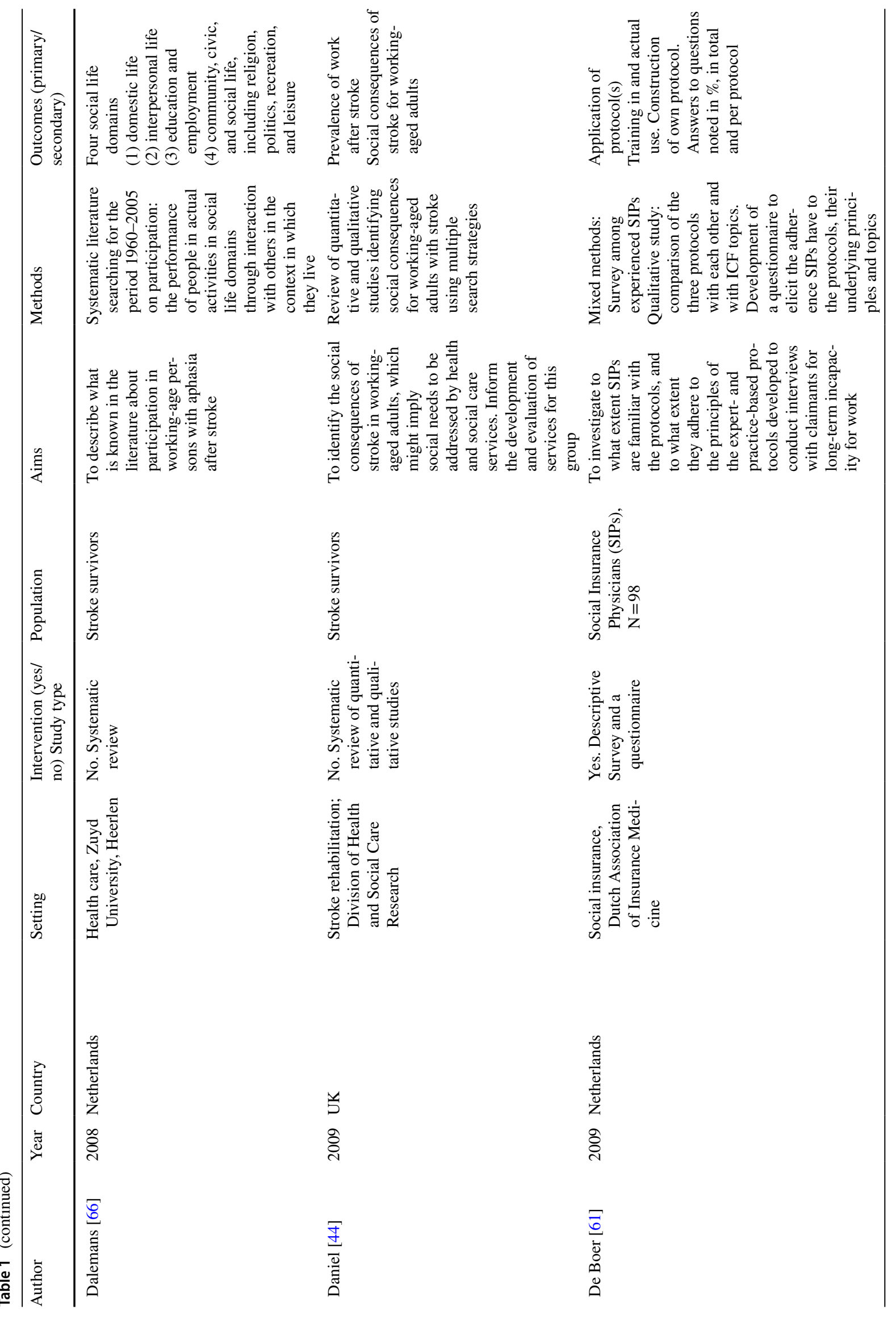




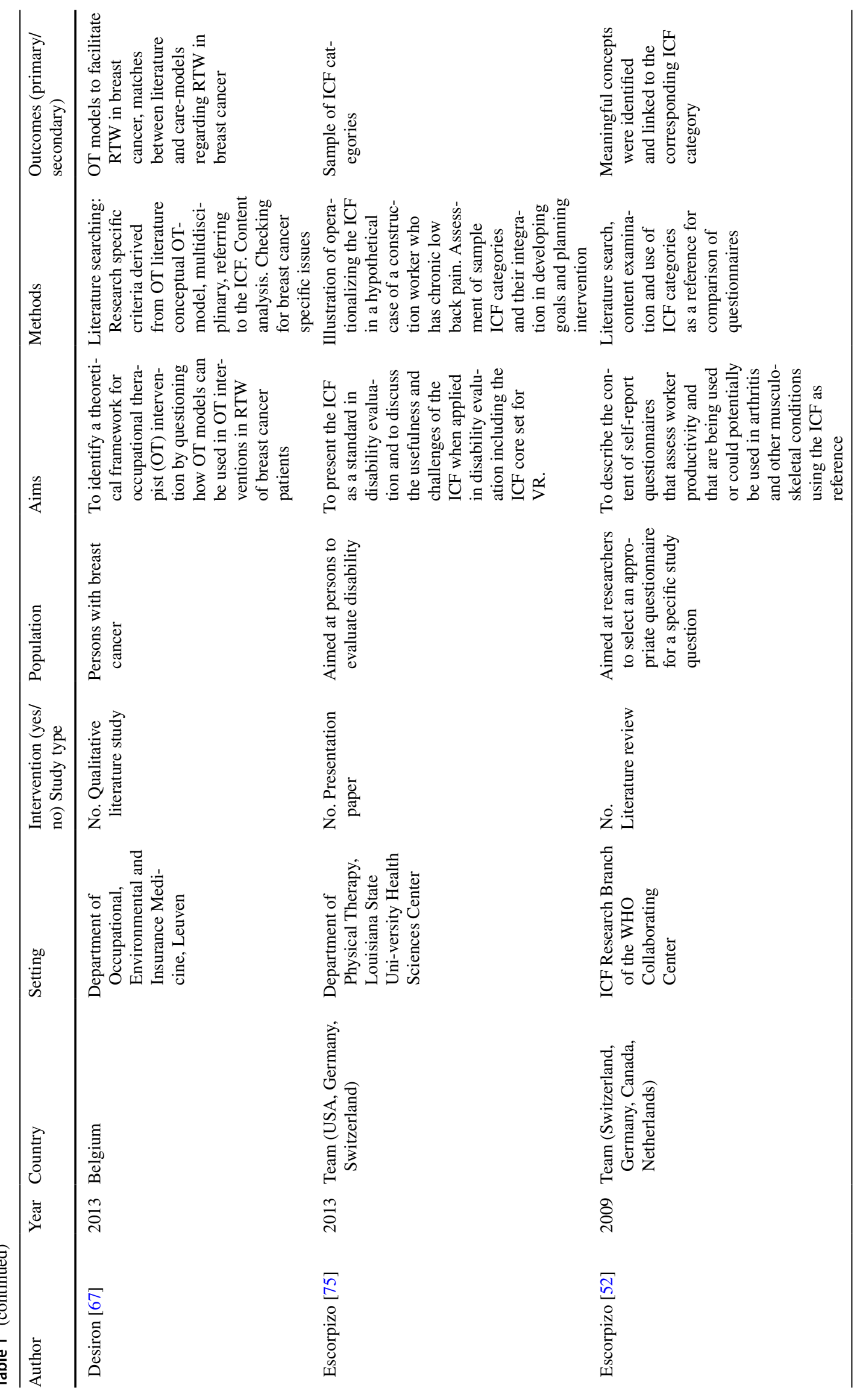




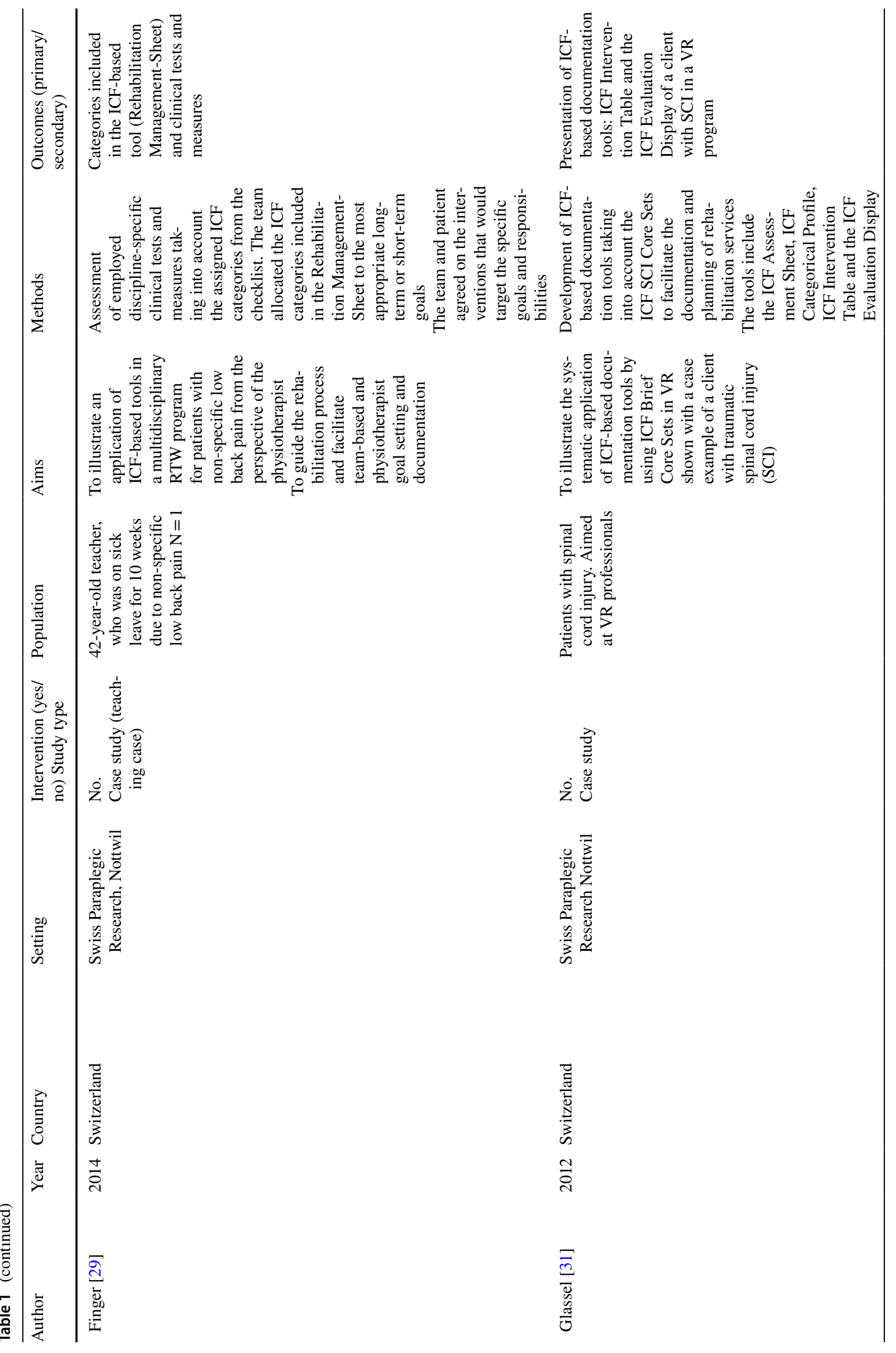




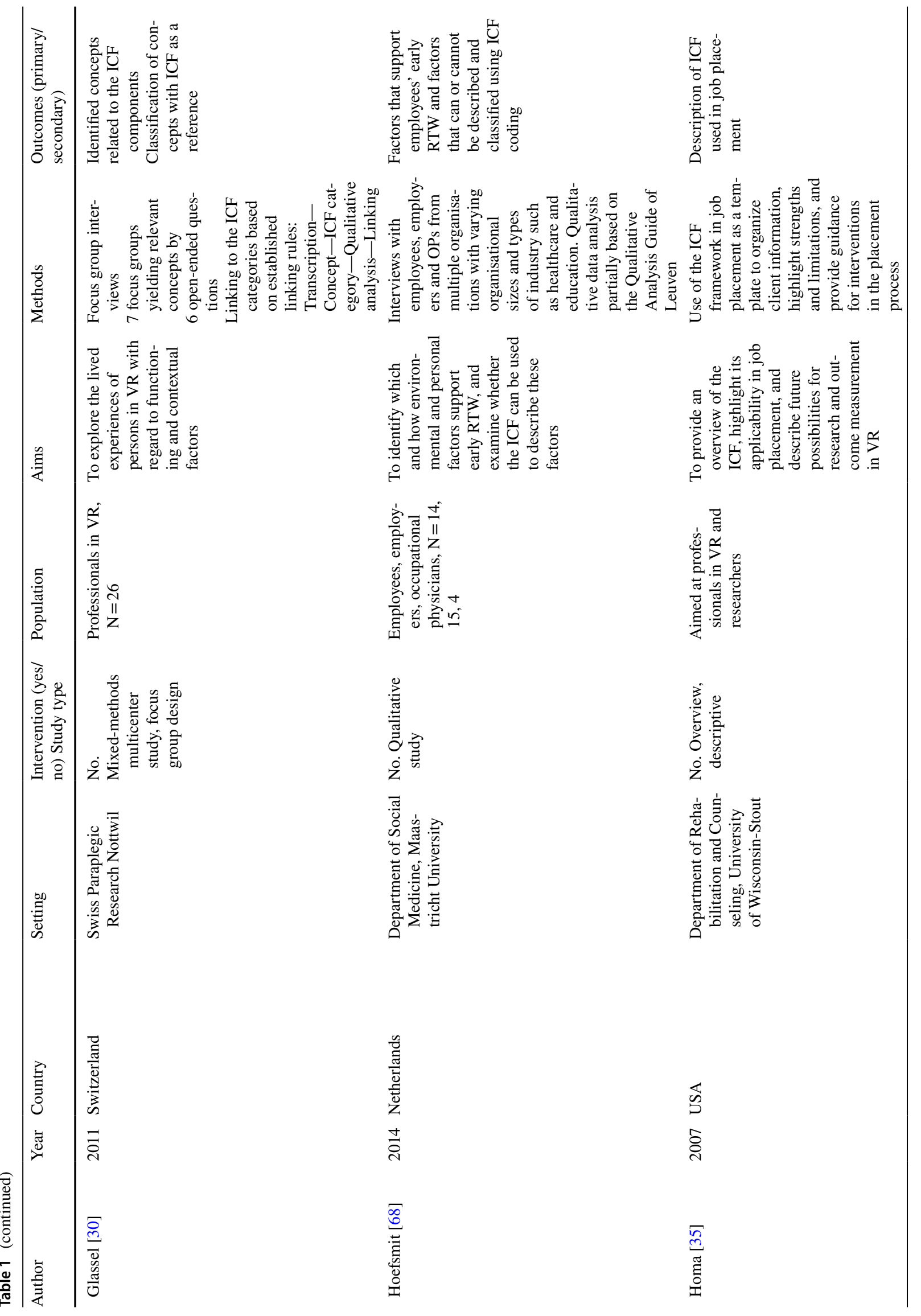




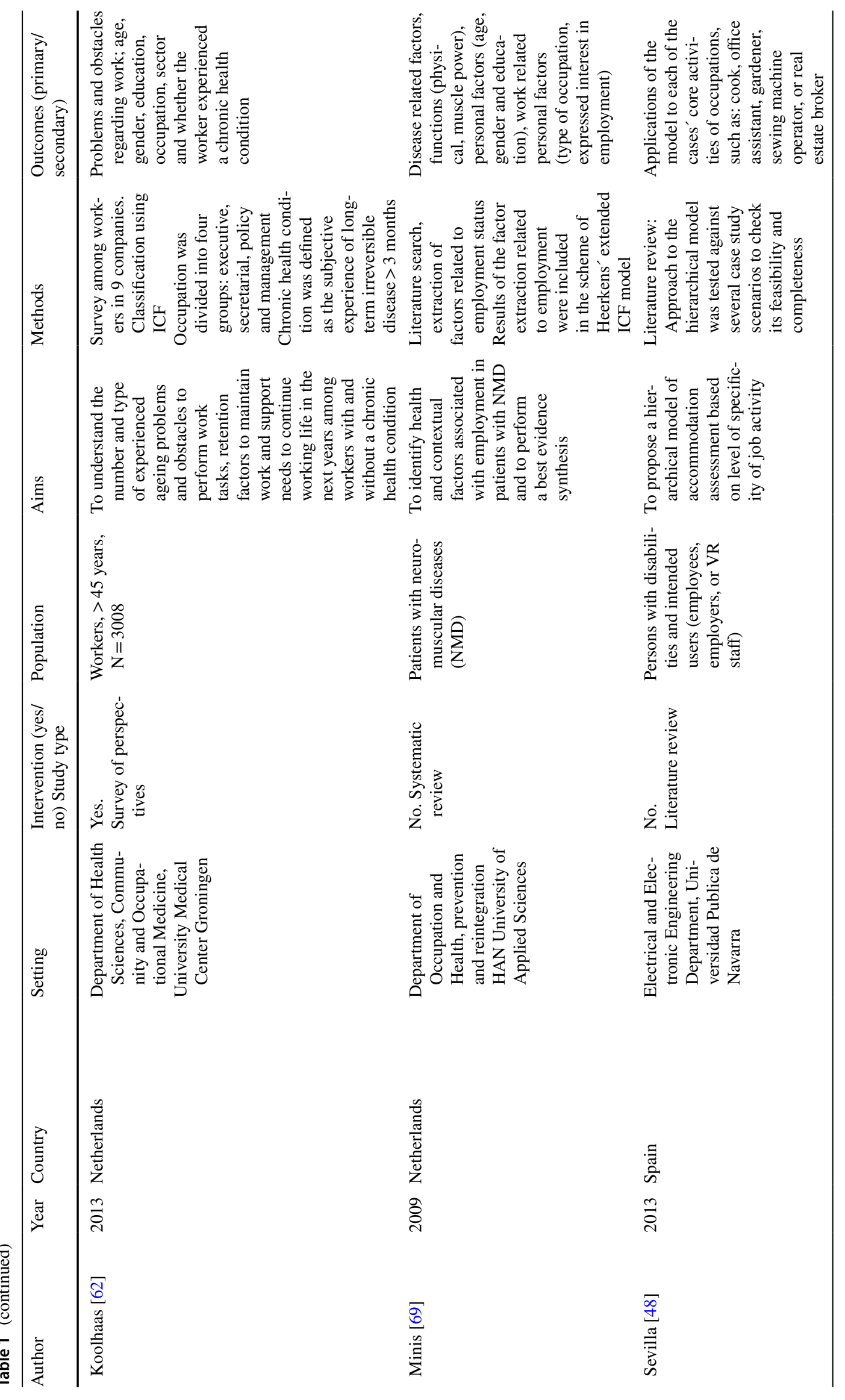




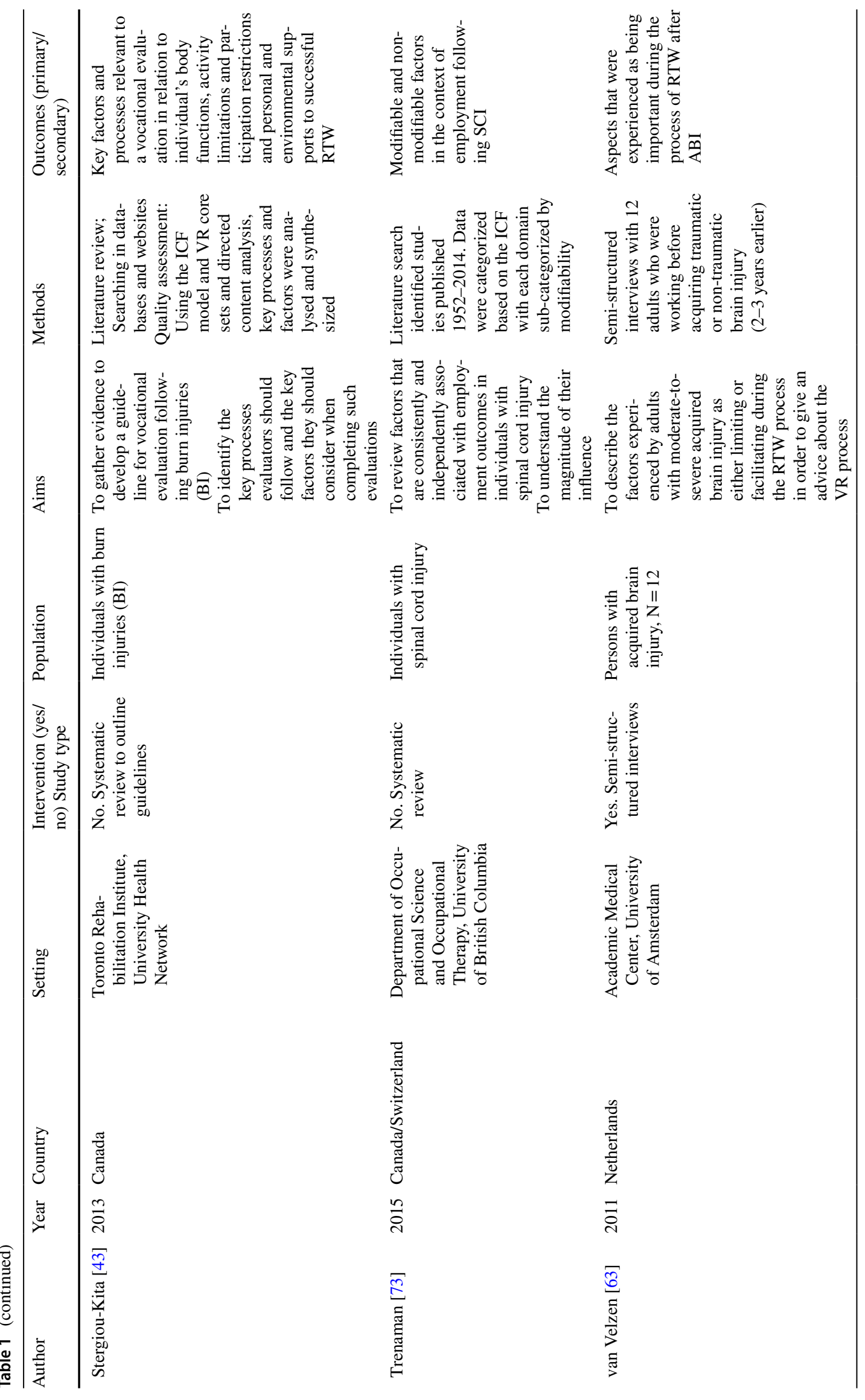




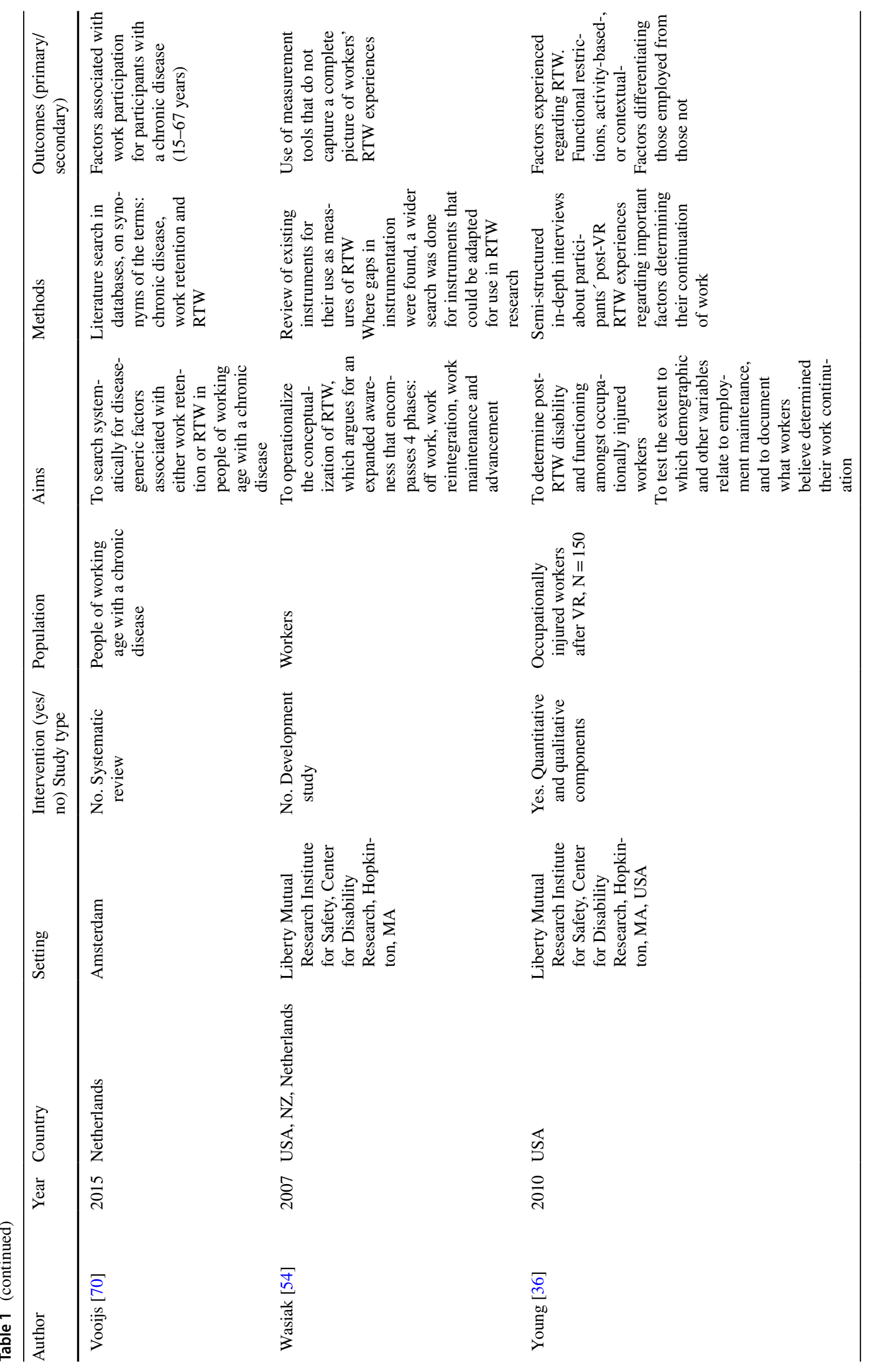




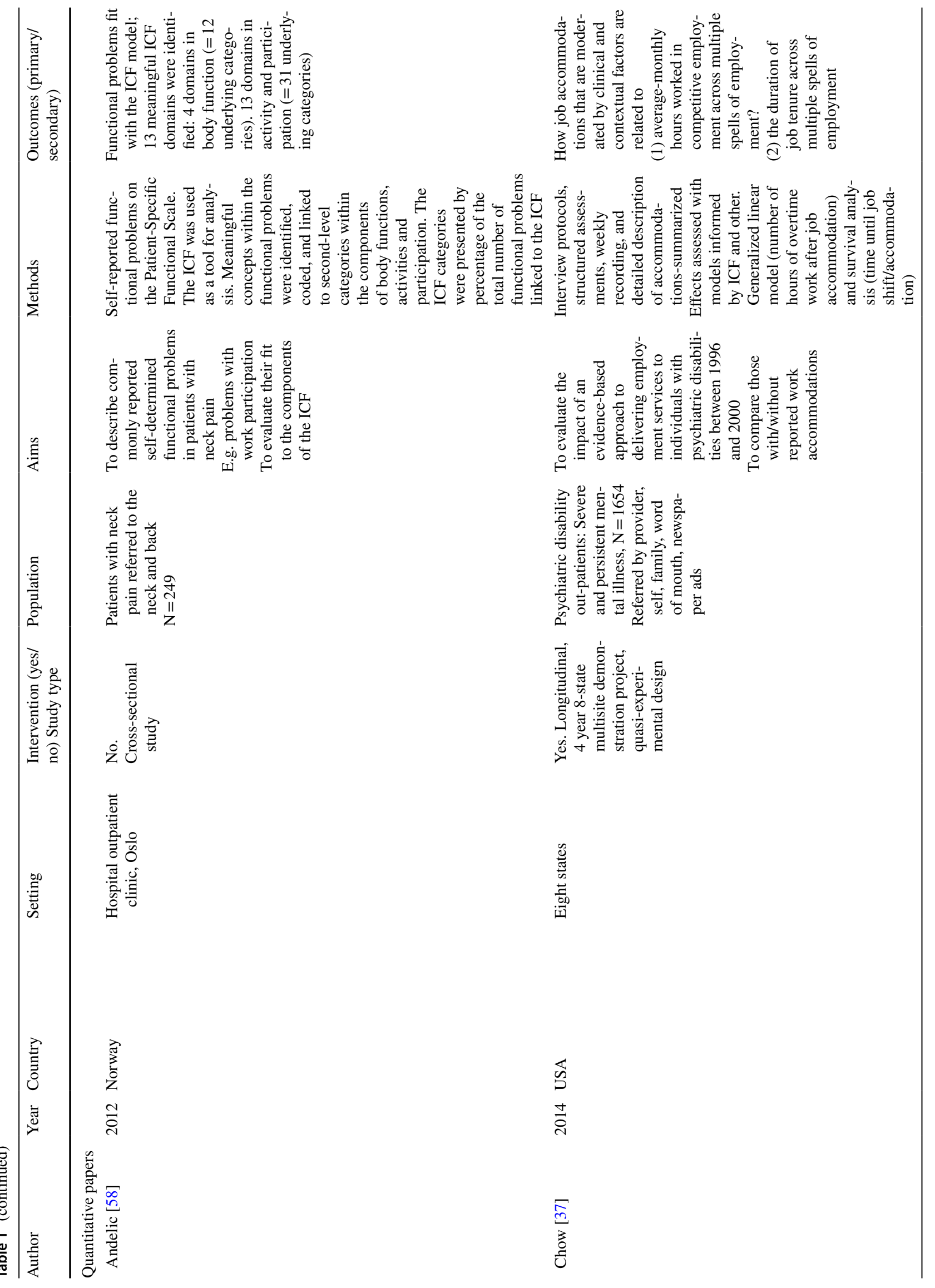




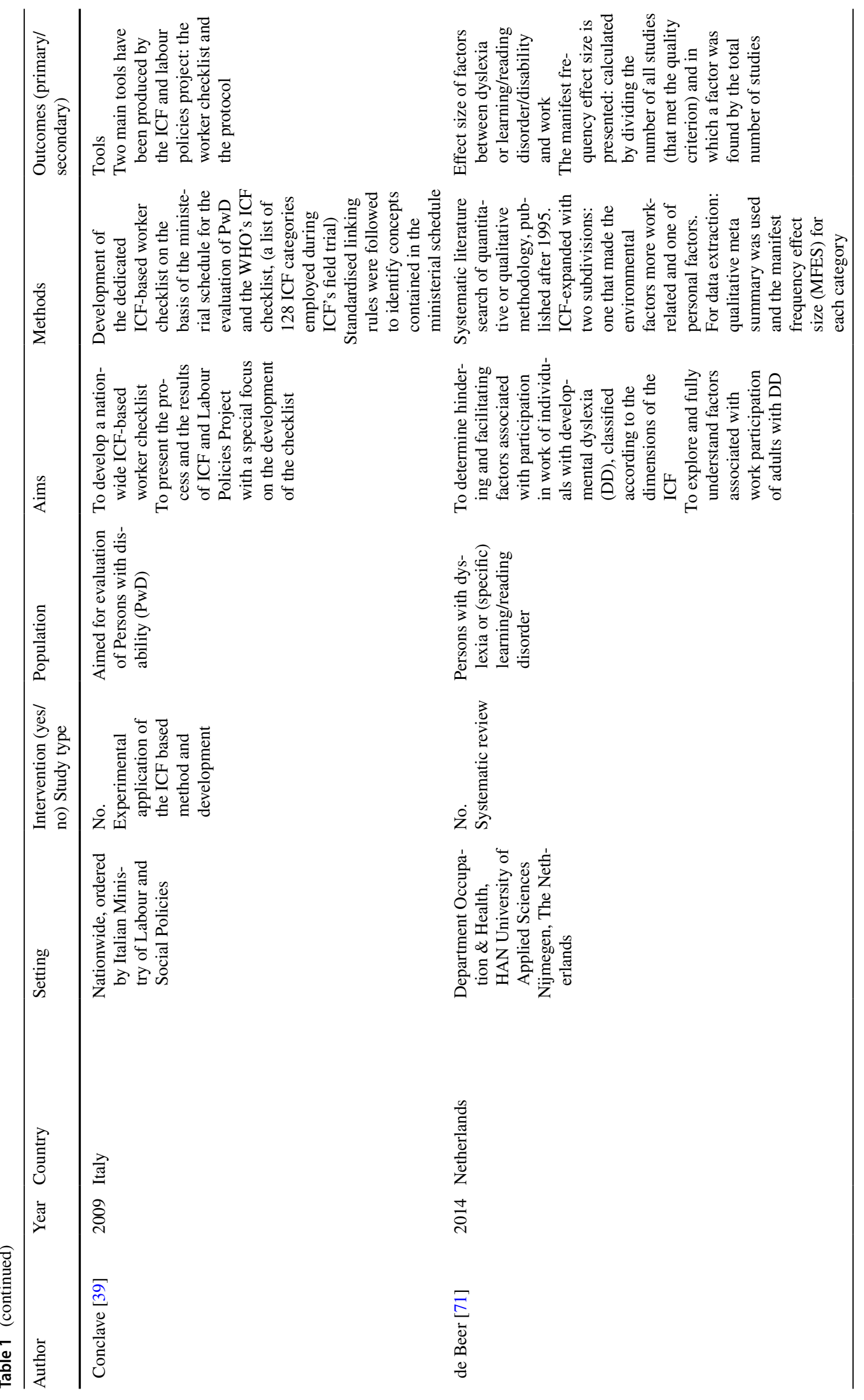




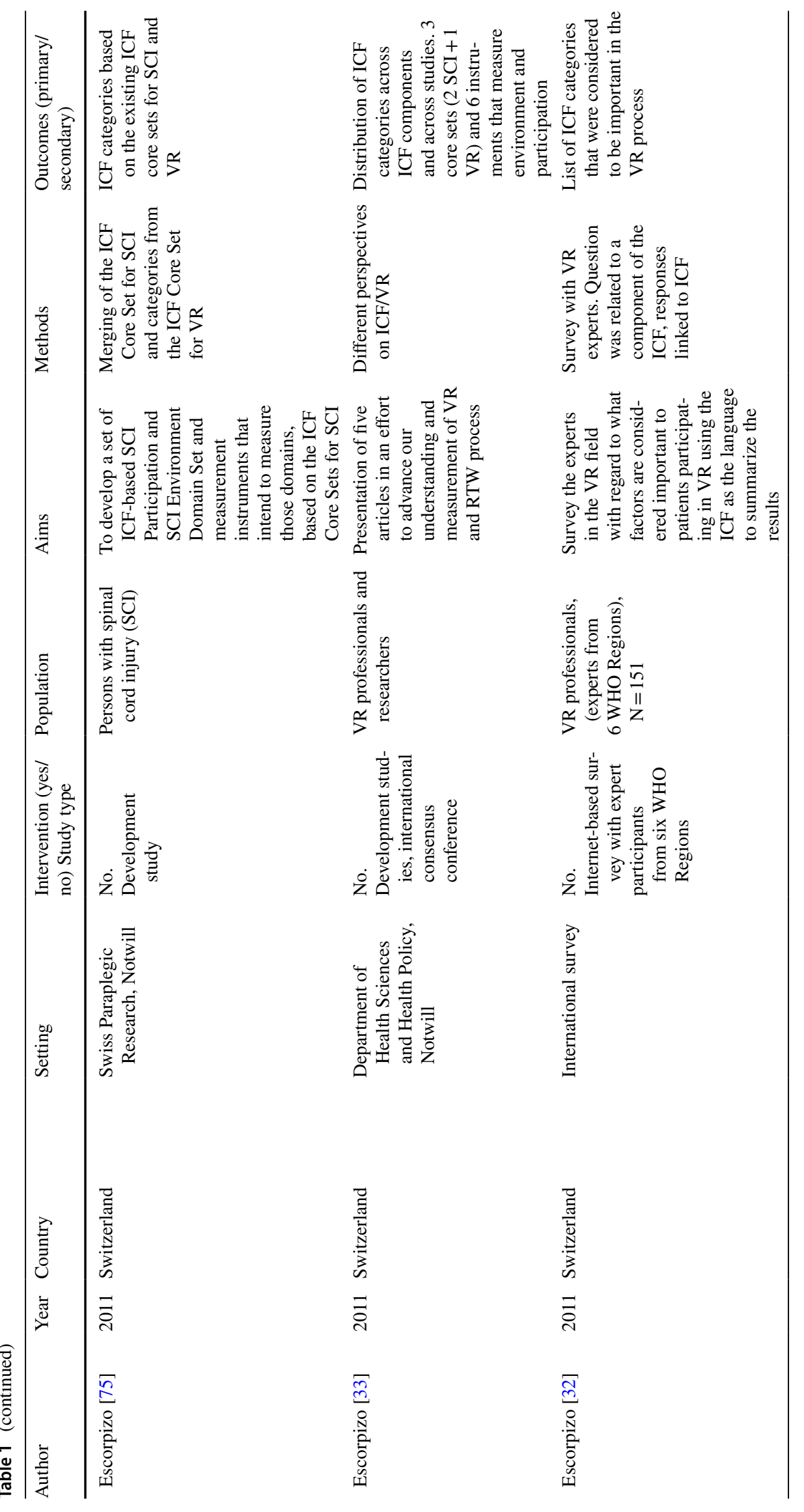




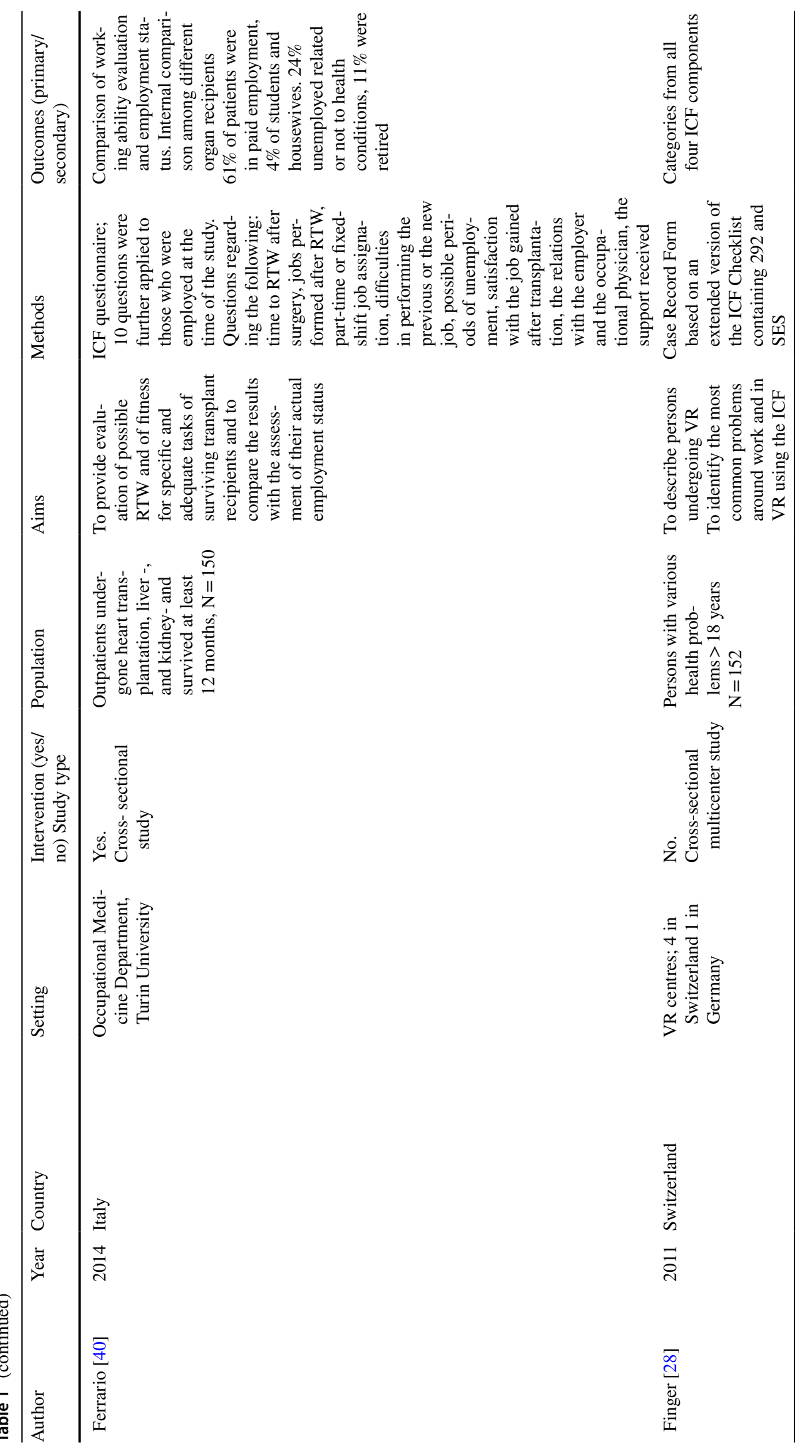




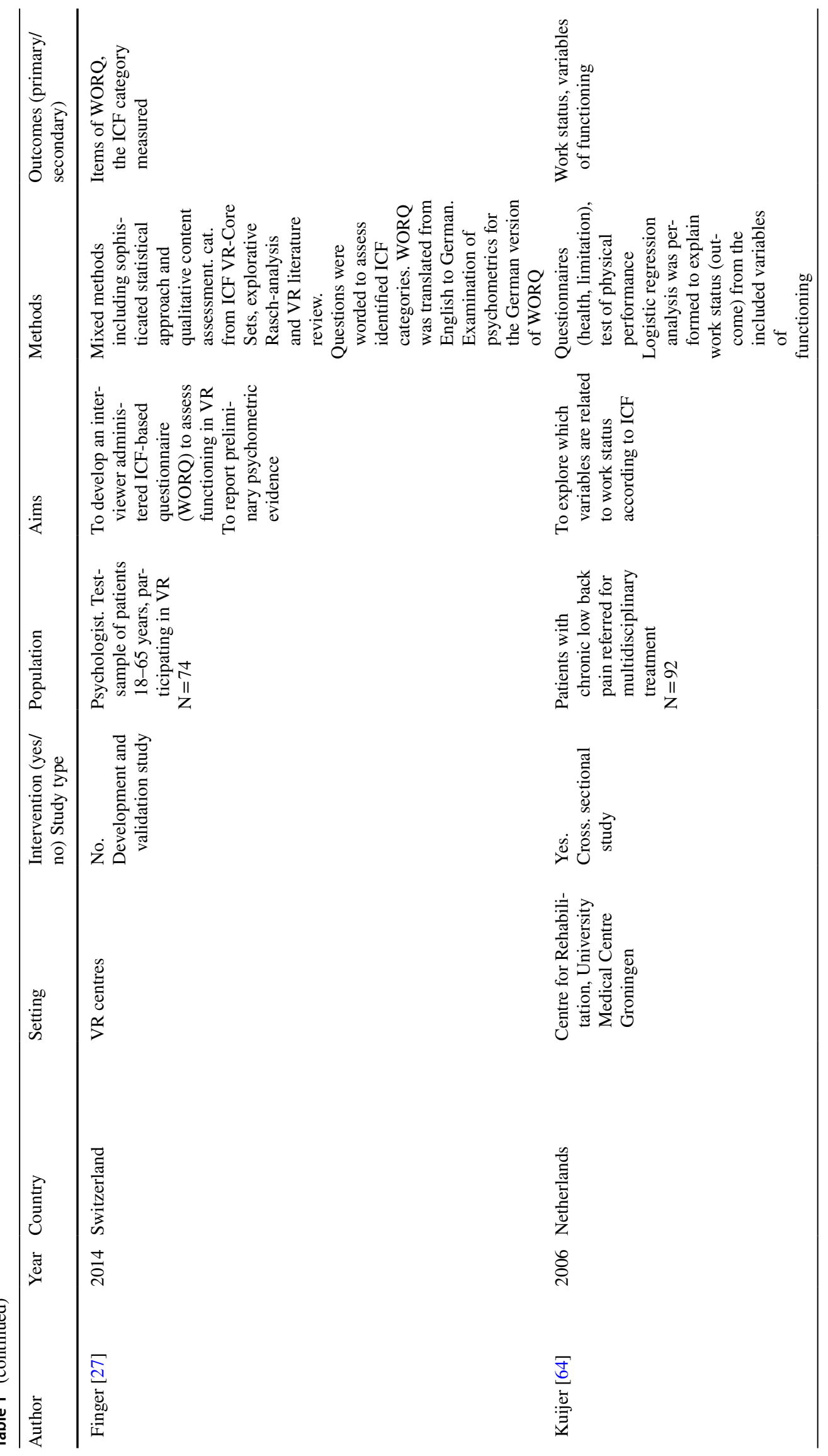




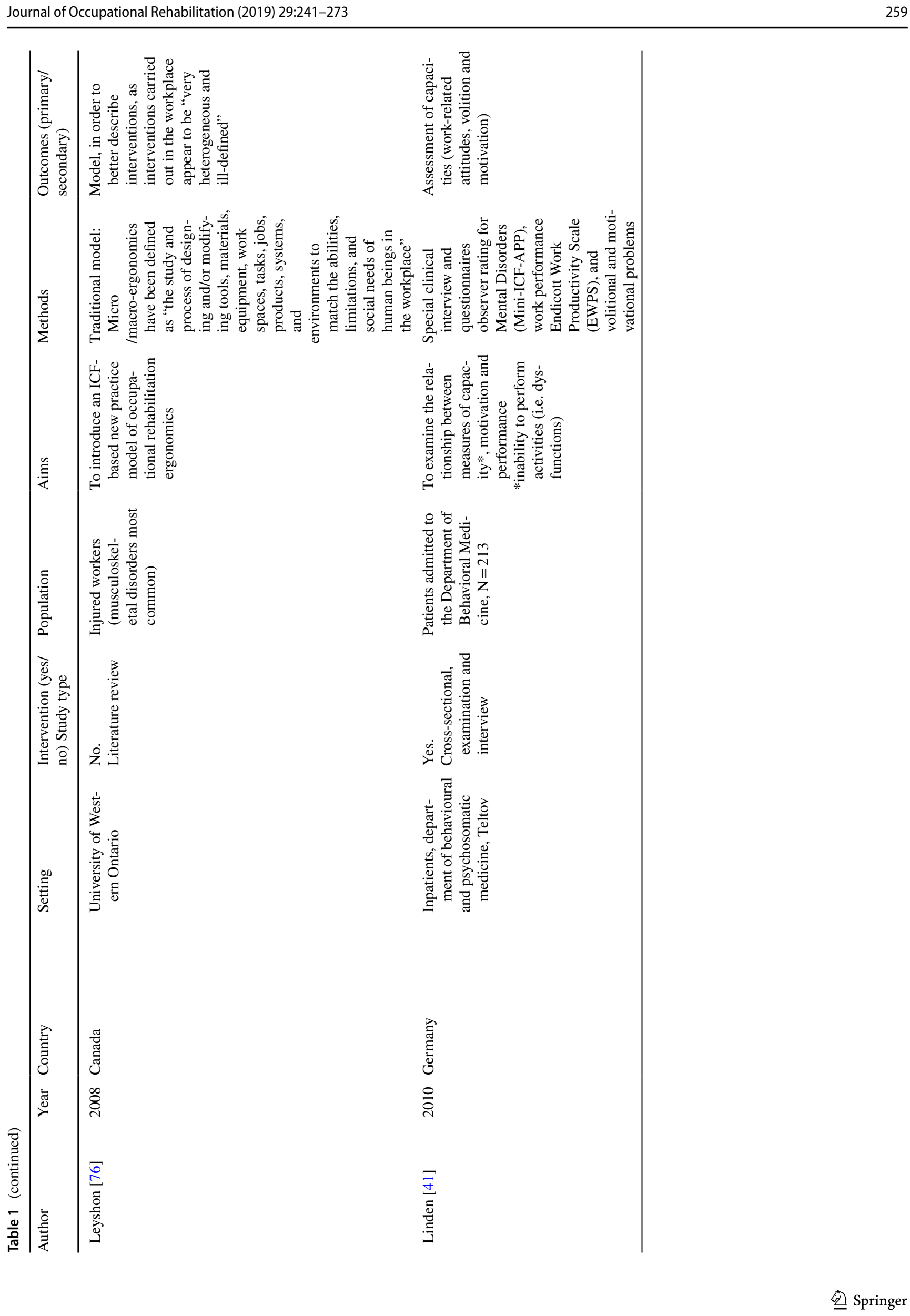




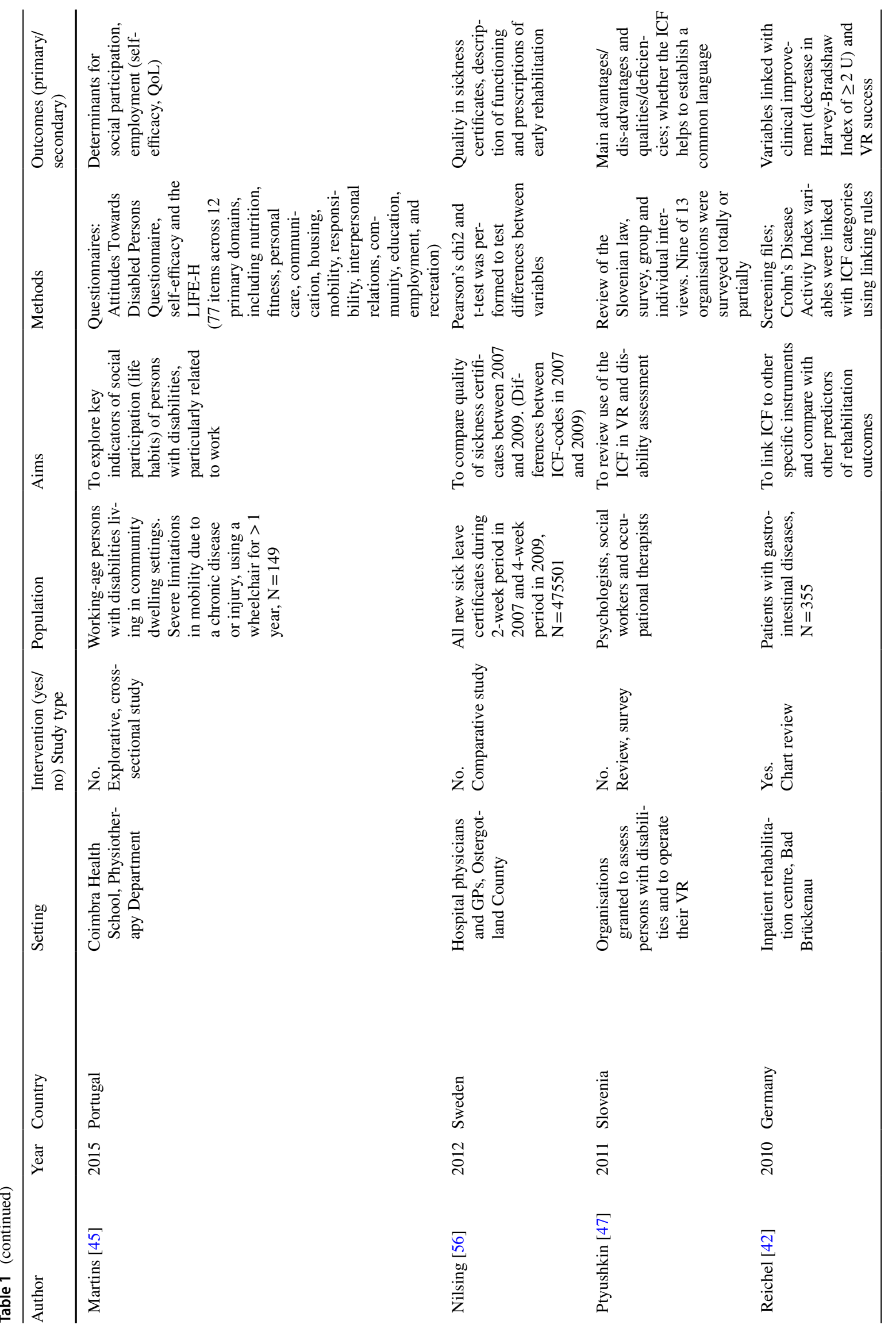




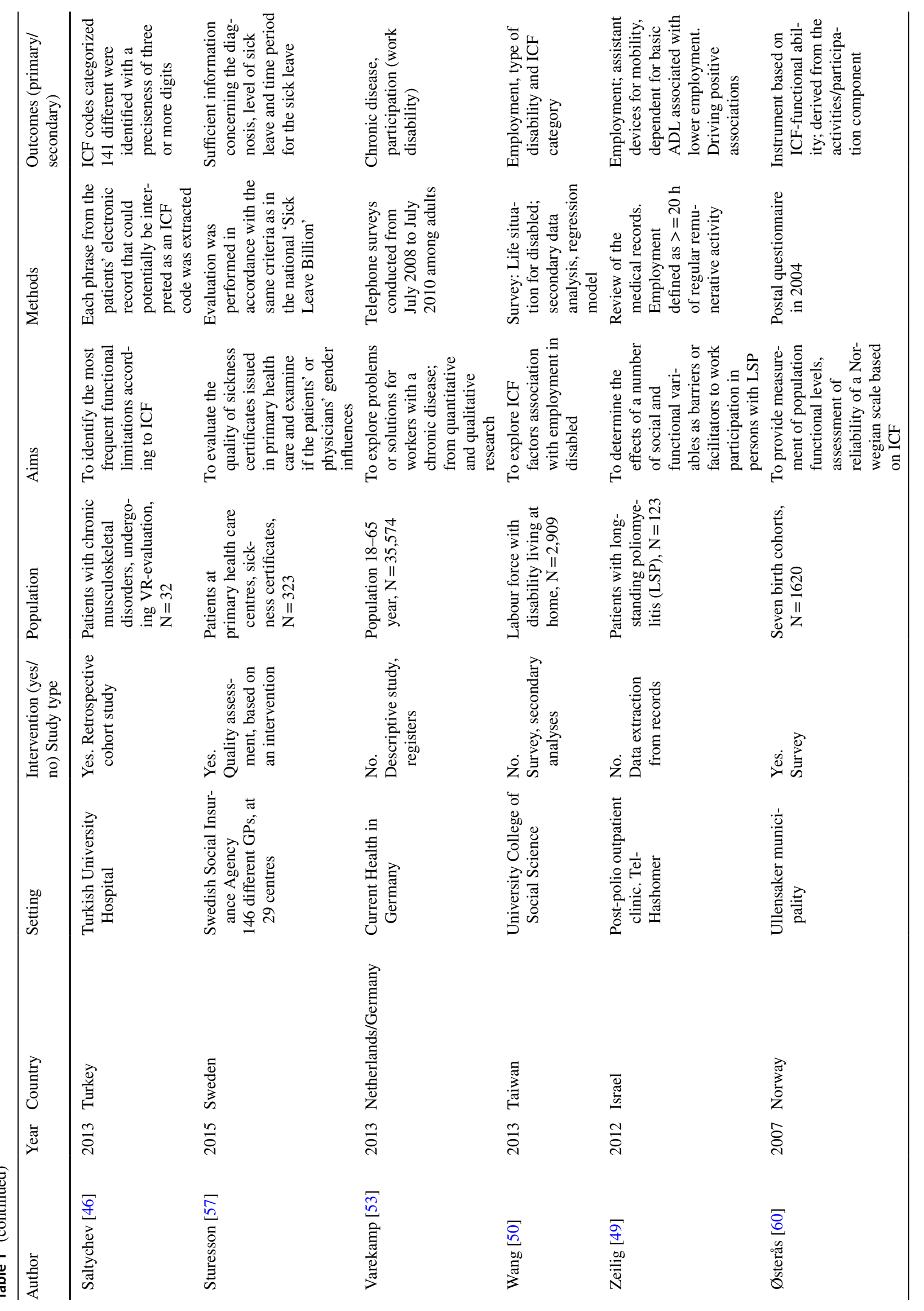




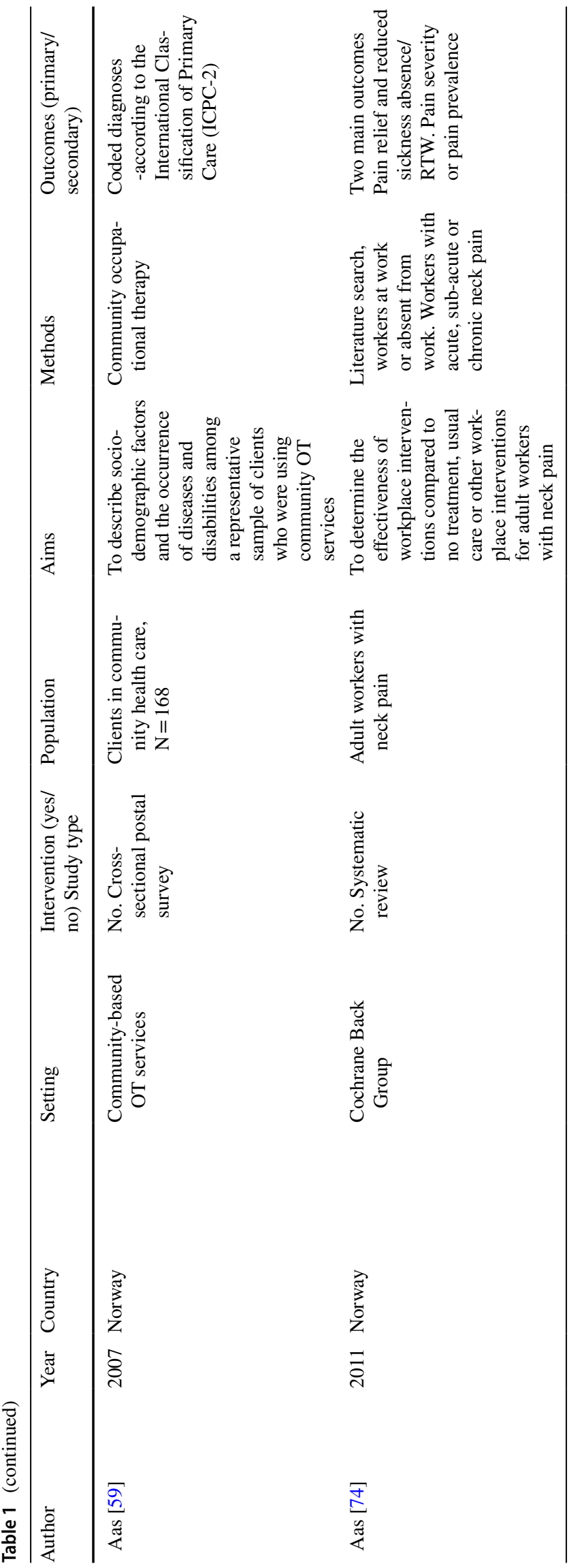

VR professionals [32, 39, 40, 42, 46, 47, 59], e.g. psychologists, social workers, technologists, occupational therapists, occupational physicians, education counsellor, rehabilitation counsellor. Two papers involved health professionals and patients [28], and solely health professionals [27], respectively. A paper described all professionals involved in rehabilitation research (experienced physiotherapists, certified physiotherapist/movement scientist, research assistant) [64], another paper involved independent insurance specialists, who were trained to assess the quality of information in sickness certificates [57].

\section{How the ICF Inform Assessment of Functioning}

Regarding to what extent the ICF informed professionals' assessment of functioning; several papers reported discussions on the ICF's applicability for VR, service delivery, and RTW support. As examples were papers reporting on potential benefits of the ICF: to structure and phrase disability evaluation in the field of social insurance [26], on tracking risk factors for disability amongst the self-employed [65], highlight its applicability in job placement [35], and to identify the most common problems around work and in VR.

One paper concluded that a questionnaire based on the ICF proved to be a "useful framework that can be used for research but also by occupational physicians in their usual practice after specific training" [29]. A paper reported on an expert survey on use of the ICF as the language to summarize the results in VR [32]. Another paper concluded, that although the procedure using the ICF was "complex, time-consuming, and requires specific training of the staff involved in its use"; the occupational physicians were provided with a standardized procedure to evaluate working ability and suggest re-employment for transplant recipients [40].

A paper described how VR professionals used the ICF to guide assessment in the job placement process and used the appropriate ICF domains and categories as a template to determine what specific information needed to be obtained, and how to organize it in a systematic way. Thus, an interview format informed by the ICF structure enabled the professionals to highlight the needs for assessment information [35].

\section{Criticism of the ICF}

One paper involving several health and non-health professionals concluded, that disadvantages of the ICF are the "complicated terminology, perceived subjectivity of the assessor in coding" and that 'it is too bulky' [47]. Another paper described factors that support employees' early RTW and reported that some factors cannot be described and classified using the existing coding system of the ICF [68]. 


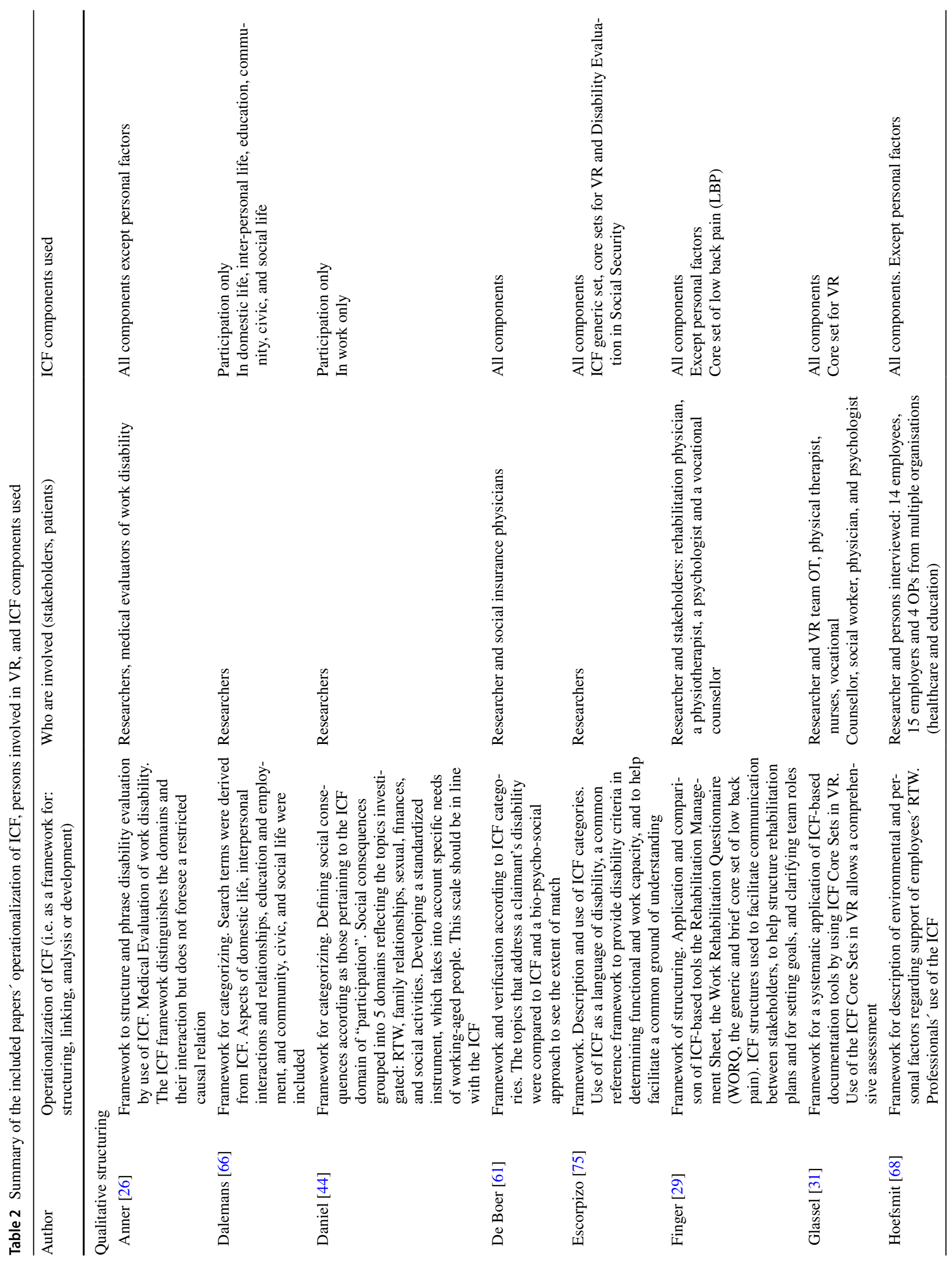




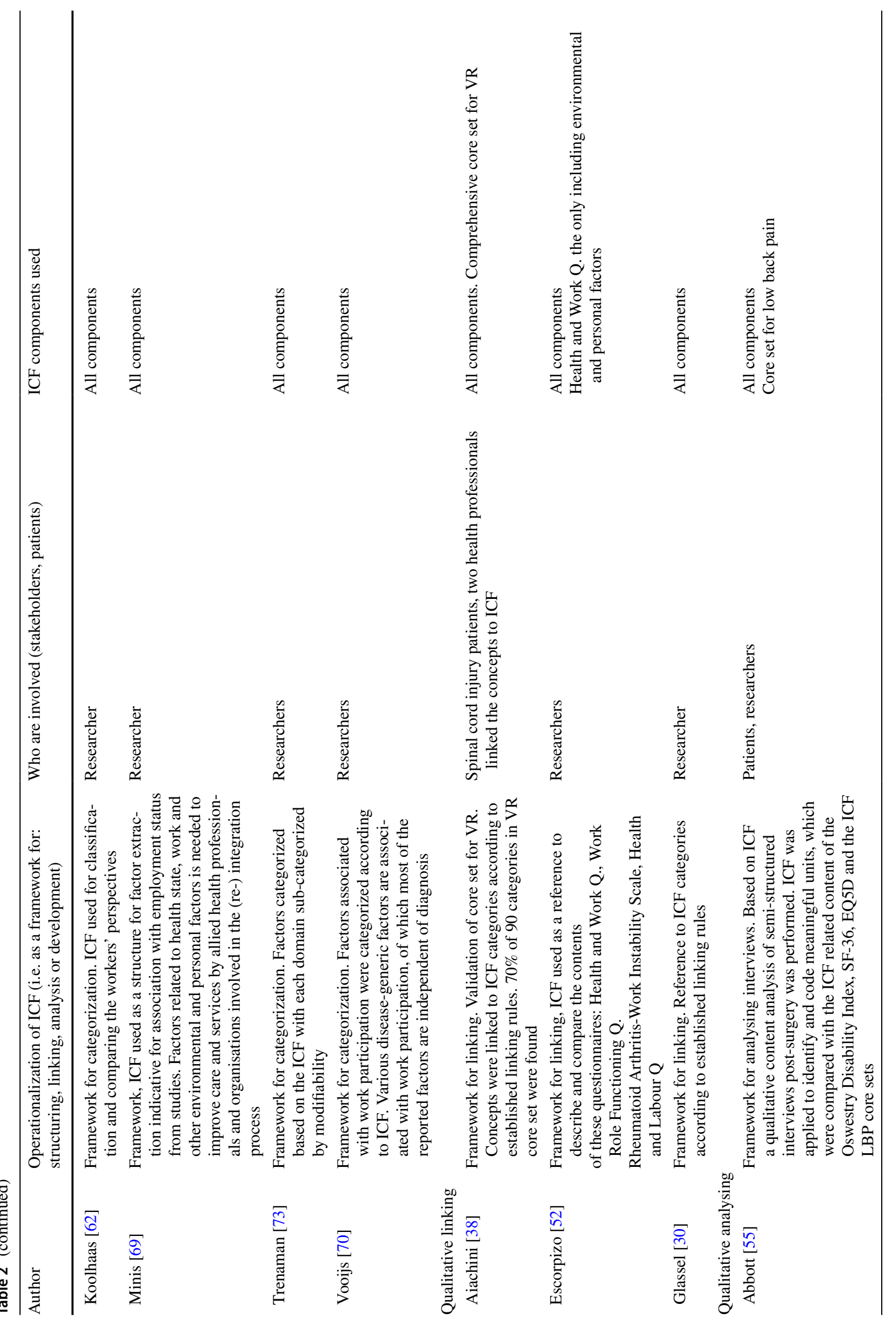




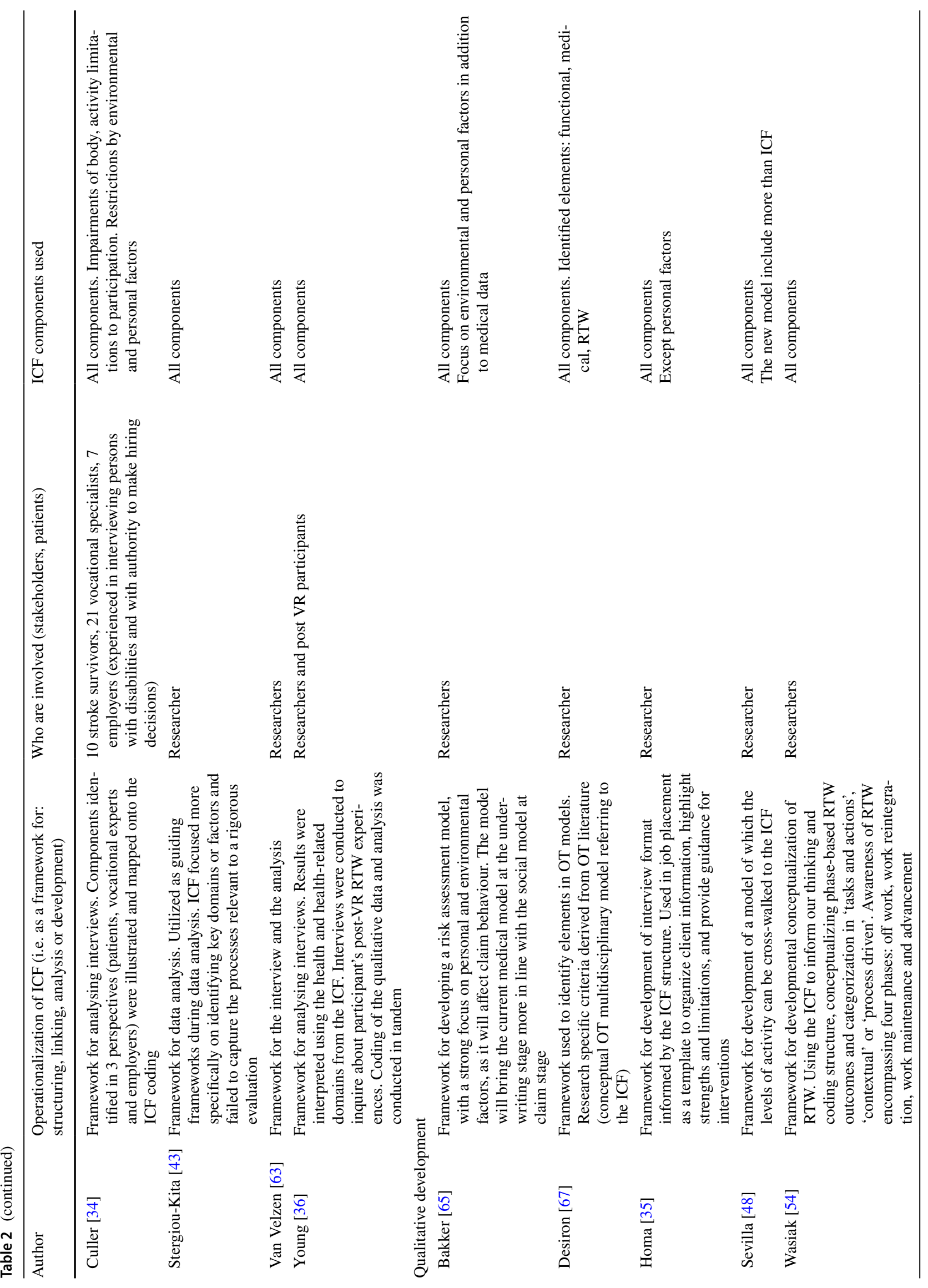




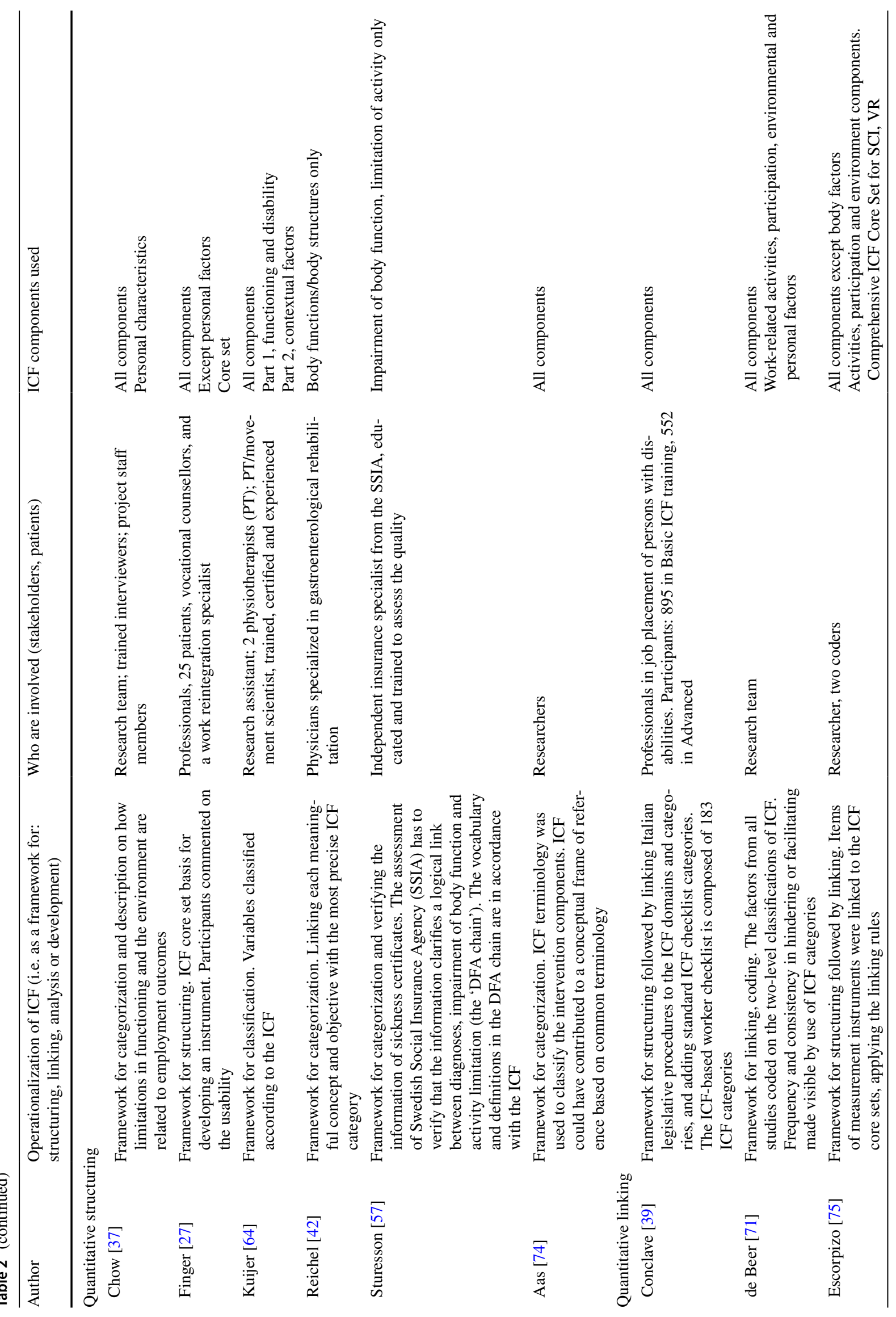




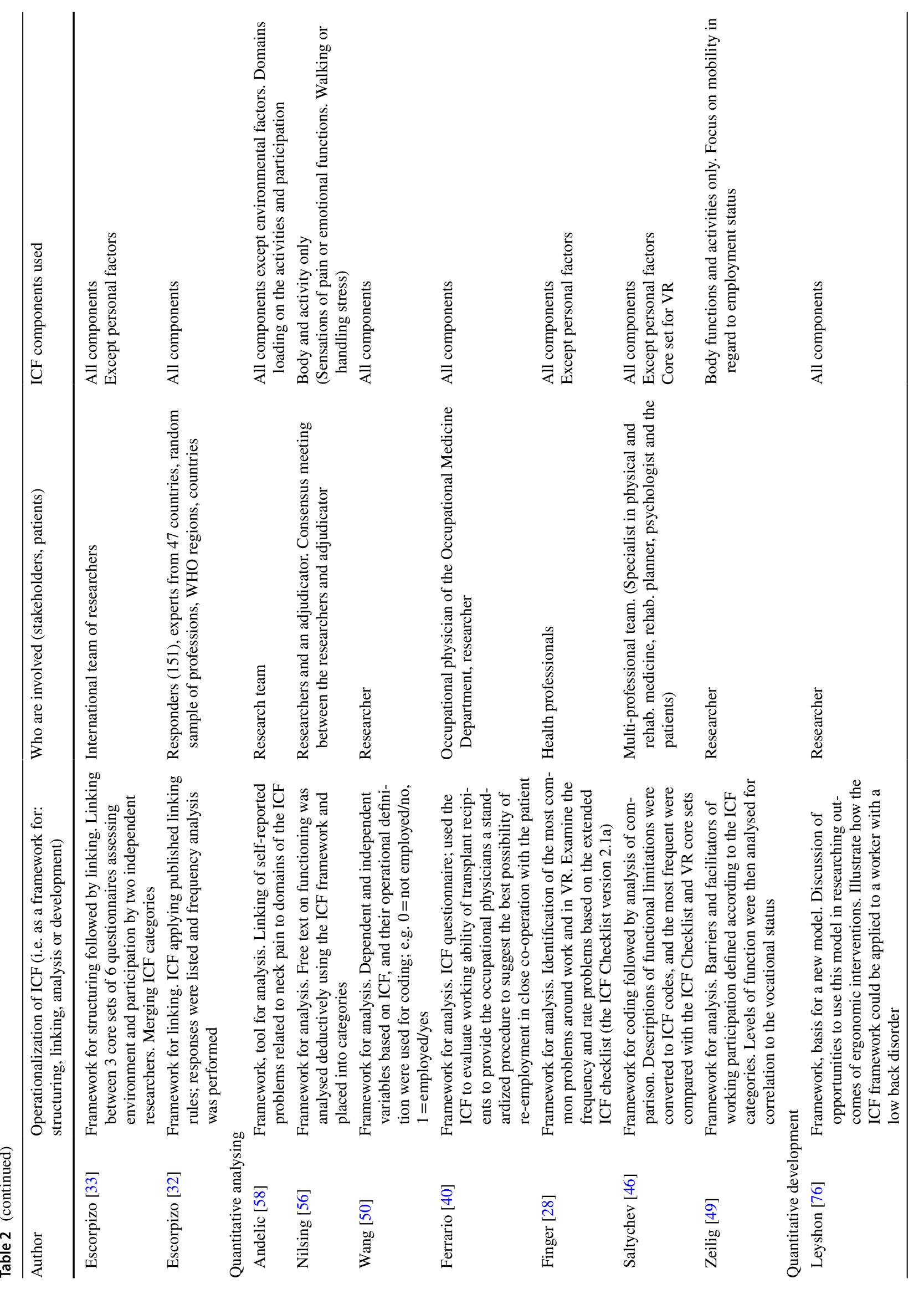




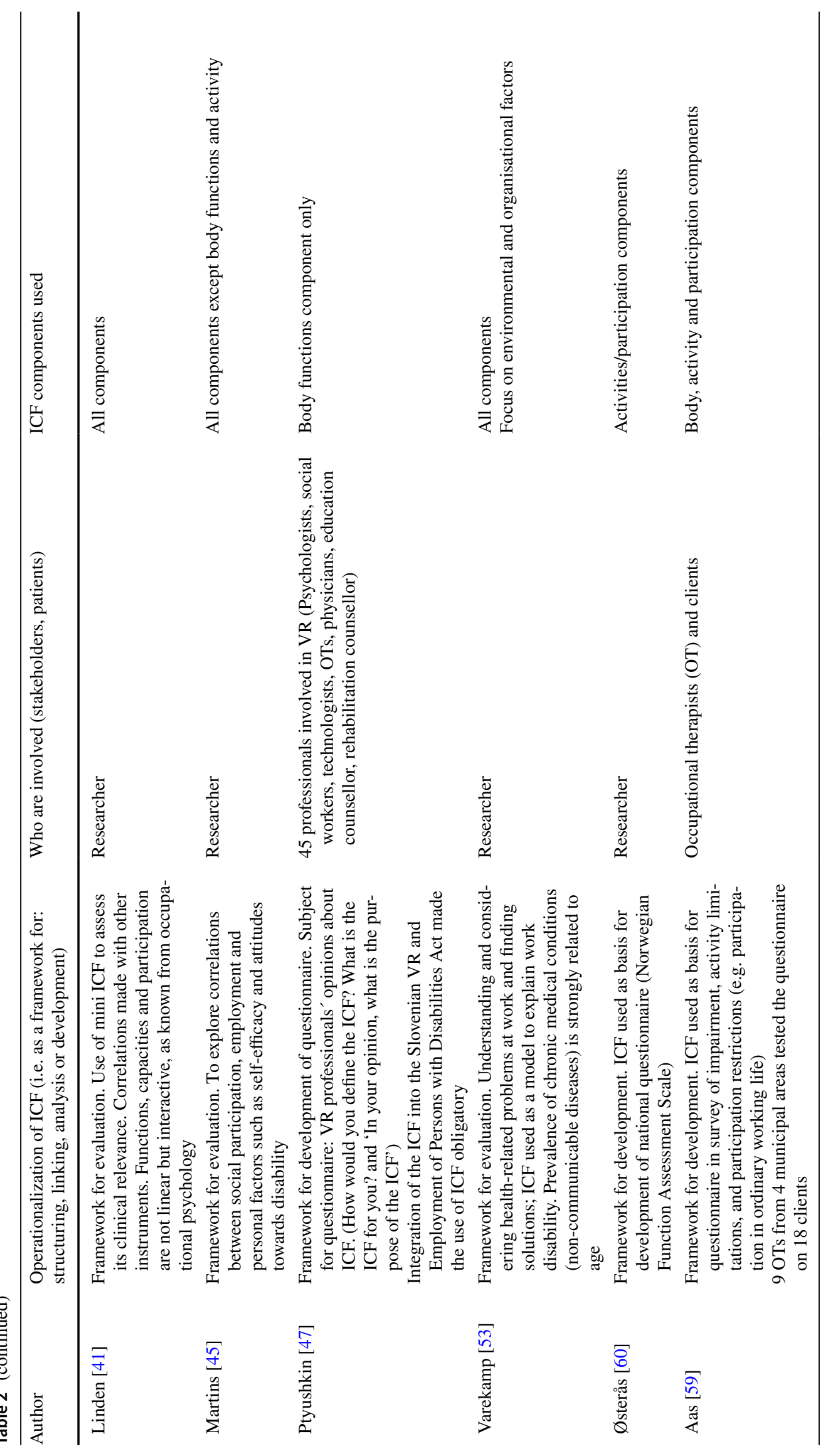




\section{Which of the ICF Components and Core Sets are Considered When Functioning is Evaluated in VR?}

Except in 10 papers all the ICF components were described. Two papers commented on personal factors, despite the fact they are part of the ICF there are no categorizations [29, 35]. Only two papers described the component participation [44, 66]. One paper described all components but environmental factors [58]. Six papers evaluated the body functions component only [42, 47, 49, 56, 57, 59], and three papers reported on all components except body functions or participation components [45, 60, 75].

Seven papers used the ICF core set $[27,29,30,38,46,51$, 55], among which four studies reported on the core set for VR [30, 38, 46, 72]. The VR core set was used for validation of another ICF core set [38], development of ICF-based documentation tools [30], comparison of the most frequent ICF coding of functional limitations with the ICF Checklist and VR core sets [46].

\section{Discussion}

The ICF was primarily used in Western VR contexts. The ICF used as a framework was the most prevalent operationalizing of ICF (18 papers), whereas linking, analysing and developing appeared in 8,12 and 12 papers respectively. As 32 of the 50 included papers were reviews the predominant profession involved in ICF were researchers. Among the original papers no single profession stood out as particularly ICF users. In general the ICF enabled the various professions involved in VR in a structured way to obtain relevant need assessments and communicate this across professions. The majority (40) of papers described all factors, which support the bio-psycho-social approach. However, it was not clear if the ICF was suitable as an instrument for goal setting and evaluation as merely single papers mentioned these properties. Moreover, the ICF was criticised for being time consuming. Unexpectedly four papers described the ICF components body and acidity only, despite participation and environmental factors seem inseparable from VR. The VR core set was not the primary tool when functioning was evaluated within VR.

Compared to the findings in another review where qualitative papers only constituted a tenth [10], and despite some papers with a mixed study designs were defined as qualitative in this review, the number of qualitative and quantitative papers was more balanced in this review.

The ICF defines functioning as the interaction between an individual and that individual's environmental and personal factors; accordingly a paper illustrated the problems of functioning in a person with low back pain by use of the framework [75].
The ICF is seen as a useful tool for describing, comparing and contrasting information from outcome measures and clinical patient reports across diagnoses, settings, languages and countries [77]. A review showed that linking health and health-related information to the ICF is a useful way to apply the ICF in research [77].

Evaluation of functioning is relevant early in VR [8], and this review found several presentations of the applicability for VR and use of the ICF to examine and measure VR processes and outcomes. The findings show that the ICF was useful in providing a clear description of the consequences of diseases, and of the factors that can be described using the ICF coding, which may potentially support the VR professionals, e.g. factors that support employees' early RTW [68]. The ICF can help VR professionals gain a more precise understanding of the impact of disability on individuals' ability to perform life tasks or activities. Thus, the ICF might contribute to a more informative description in multiprofessional assessments, because healthcare professionals have different perspectives on the health-care process [57]. However, a paper concluded that in primary care there seem to be a lack of knowledge about the ICF, and that increased cooperation between GPs and other health-care professions may require learning as well as a change of attitudes [57].

Furthermore, an ICF-based questionnaire regarding time to RTW, work difficulties, job satisfaction, and work relations was reportedly useful for occupational physicians assessing patients after transplant procedures [40]. Thus, the ICF framework provided an effective evaluation of possible RTW and capabilities of these patients, who had undergone transplants and survived at least 12 months. However, the procedure of for assessment of self-reported work ability was reported as complex and required specific training of the staff involved [40].

The present review illustrates how the ICF may support development of questionnaires [59, 60], like e.g. the Work Rehabilitation Questionnaire (WORQ). The WORQ has proven to be a valuable instrument within VR [27], e.g. as to support the physiotherapist's role within the rehabilitation team by enhancing transparency in goal setting and intervention planning across disciplines [29].

Although the ICF is a reasonable starting point in efforts to harmonize terminologies [33], the framework is also criticised for limitations. This scoping review reported on the ICF components only. However, each of the components (except for personal factors) is further divided into domains and underlying categories providing more detail of a component. The ICF coding system is intended to describe a person's functioning at a specific time, in that person's normal circumstances and environment. Qualifiers are built into the coding system to indicate the magnitude of the impairment, limitation or restriction for each category. 
A review on the use of ICF in outcome measures used within VR identified that a third of categories were related to body functions [10]. This review also identified some papers solely reporting on body functions, which is not representing a bio-psycho-social approach. It should be recognized that the ICF is limited with respect to comprehensive descriptions of work disability, e.g. the cause why a person is not able to work is an important part of disability evaluation. The ICF however, cannot describe causal relationship [26], and a solution may be to use the ICF combined with other instruments, which can reveal causal relations. It was pointed out that although the framework includes personal factors, they cannot be classified in the ICF [68]. This is a limitation of the framework, as e.g. motivation is important to consider when making prognosis of work ability and RTW. Personal factors also include an individual's lifestyle, habits, social background, education, life events, race/ethnicity, sexual orientation, and coping mechanisms [43]. Work participation relies on both personal and environmental factors, which in addition to the medical data, affect functioning and participation, e.g. a paper concluded these factors affect claim behaviour [65]. Factors that are likely to be emphasized in a VR setting are within the components: activities, participation and environmental factors [35]. A Cochrane review found a lack of interventions targeting the ICF-domains: attitudinal and social environment [74]. However, this review found only a few papers lacking the environmental factors.

Unexpectedly, the review revealed a limited use of the ICF VR core sets. These include environmental factors that may prove to be useful when disability evaluation and work capacity is being assessed. However, a validation study of the comprehensive VR core set concluded, that it was insufficient from a sole physiotherapist perspective, there was a need for additional ICF categories. Although the VR core set was considered useful to clarify responsibilities and for communication in a multidisciplinary setting, it was too comprehensive for mono-disciplinary use of physiotherapist [78]. The core sets in general were not recognized to provide an exhaustive list but rather the minimum number of categories to be assessed [8]. Therefore practice may supply the VR core set with other instruments in order to fully assess functioning.

\section{Strengths and Limitations}

One strength was the inclusion of both qualitative and quantitative papers from multiple settings and countries. Furthermore, the scoping review format offers an overview of study findings in a field where the knowledge is still limited.
The reviewers experienced difficulties in study selection, despite the method by two reviewers and how to ensure eligibility criteria is a limitation. In a scoping review the extracted data is based on information provided in individual papers without critical assessment, which is a limitation despite no scope of synthesizing evidence. Furthermore, the categories of operationalization may not be mutual exclusive.

The sixth and optional stage of involving relevant stakeholders was not included but may have contributed with other VR professionals' views [15].

\section{Implications for Practice within VR}

This review confirm challenges with the use of the ICF: e.g. it cannot infer causality in disability [8] and not categorize personal factors. The content of VR varies widely among countries because of differing insurance policies and disability attitudes; e.g. in Slovenia the ICF for work assessment was made obligatory but the lack of interface between the ICF and policies on VR was a challenge [47]. The ICF may be used to ensure comprehensiveness of evaluation in study populations with chronic diseases [46]. Furthermore, the framework may cover all relevant aspects of disability and may encourage the VR professionals to draw a holistic picture [26]. The ICF "corresponds closely to this ecological systems approach and could help rehabilitation practitioners more specifically and precisely identify those subsystems or environmental factors that have an impact on successful job placement" [35]. The ICF may be combined with existing measures and incorporated in daily practice [31].

\section{Implications for Future Research in Work Disability and VR}

Our findings revealed that the ICF has been applied in different settings and for different purposes, which has important implications for future research. In order to ensure comparability across studies and robust testing of hypotheses the use of the ICF needs to be clarified. Furthermore, how data are collected, assessed and classified based is lacking in the field of VR. Hence, research on the practical utility of the ICF across different assessment instruments is crucially needed to inform a feasible framework development in VR.

Although the ICF provides a framework to evaluate contextual factors, this review finds there is a gap between the knowledge of the impact of personal factors and actual assessment within VR and more research is needed. 


\section{Conclusions}

The scoping review revealed use of the ICF within the field VR in 50 papers, and in various settings; e.g. hospitals, rehabilitation centres, primary health care centres, sickness certificate registration offices, and research departments. The operationalization of the ICF was described in four ways: for structuring information, linking of categories or content, analysis according to the ICF framework, or development of instruments or models based on the ICF.

A majority of papers were reviews and involved researchers only, whereas different stakeholders and VR professionals were involved in the interventions. The components of the ICF that depict functioning and disability were largely incorporated in the VR research. This observation points to the benefit of using a common set of ICF components to inform the selection of set of measurement instruments. Such a process would lead to a single set of standardized measures looking at similar outcomes and make comparability across studies possible However, more research is needed to develop and validate instruments measuring relevant domains including personal factors and to standardize and ease the VR professionals' use of the ICF.

Acknowledgements We thank the research librarian Helene Sognstrup Aarhus University Library, for providing support in the search strategies for this review.

\section{Compliance with Ethical Standards}

Conflict of interest A.H. Momsen, C.M. Stapelfeldt, R. Rosbjerg, M. Labriola, R. Escorpizo, and M. Bjerrum declare that they have no conflict of interest.

Research Involving Human and Animal Participants This article does not contain any studies with human participants performed by any of the authors.

Open Access This article is distributed under the terms of the Creative Commons Attribution 4.0 International License (http://creativeco mmons.org/licenses/by/4.0/), which permits unrestricted use, distribution, and reproduction in any medium, provided you give appropriate credit to the original author(s) and the source, provide a link to the Creative Commons license, and indicate if changes were made.

\section{References}

1. Bultmann U, Sherson D, Olsen J, Hansen CL, Lund T, Kilsgaard J. Coordinated and tailored work rehabilitation: a randomized controlled trial with economic evaluation undertaken with workers on sick leave due to musculoskeletal disorders. J Occup Rehabil. 2009;19(1):81-93.

2. Escorpizo R, Reneman M, Ekholm J, Fritz J, Krupa T, Marnetoft $\mathrm{S}$, et al. A conceptual definition of vocational rehabilitation based on the ICF: building a shared global model. J Occup Rehabil. 2011;21(2):126-133.
3. Larsson A, Gard G. How can the rehabilitation planning process at the workplace be improved? A qualitative study from employers' perspective. J Occup Rehabil. 2003;13(3):169-181.

4. Chamberlain MA, Fialka Moser V, Schuldt Ekholm K, O'Connor RJ, Herceg M, Ekholm J. Vocational rehabilitation: an educational review. J Rehabil Med. 2009;41(11):856-869.

5. Huber M, Knottnerus JA, Green L, van der Horst H, Jadad AR, Kromhout D, et al. How should we define health? BMJ. 2011;343:d4163.

6. Organisation for Economic Co-operation and Development. Sickness, disability, and work: breaking the barriers : a synthesis of findings across OECD countries. Paris: Organisation for Economic Co-operation and Development; 2010.

7. World Health Organization. How to use the ICF: a practical manual for using the international classification of functioning and health (ICF). exposure draft for comment. Geneva: WHO; 2013.

8. Escorpizo R, Brage S, Homa D, Stucki G, SpringerLink (Online service). Handbook of vocational rehabilitation and disability evaluation: application and implementation of the ICF. Cham: Springer International Publishing; 2015.

9. Marnetoft $\mathrm{S}$. The challenges of vocational rehabilitation in Sweden. Kuntoutus Fin J Rehabil. 2009;4:5-10.

10. Escorpizo R, Finger ME, Glässel A, Gradinger F, Lückenkemper M, Cieza A. A systematic review of functioning in vocational rehabilitation using the international classification of functioning, disability and health. J Occup Rehabil. 2011;21(2):134-146.

11. World Health Organization. International classification of functioning, disability and health: ICF. Geneva: World Health Organization; 2001.

12. Escorpizo R, Glässel A. The role of the ICF in physical therapy and vocational rehabilitation: contributing to developments in occupational health. Phys Ther Rev. 2013;18(5):368-372.

13. Finger M, de Bie R, Selb M, Escorpizo R. An examination of concepts in vocational rehabilitation that could not be linked to the ICF based on an analysis of secondary data. Work 2016;53(4):775-792.

14. Kaech Moll VM, Escorpizo R, Portmann Bergamaschi R, Finger ME. Validation of the comprehensive ICF core set for vocational rehabilitation from the perspective of physical therapists: international delphi survey. Phys Ther. 2016;96(8):1262-1275.

15. Levac D, Colquhoun H, O'Brien KK. Scoping studies: advancing the methodology. Implement Sci. 2010;5(1):69-77.

16. Peters M, Godfrey C, McInerney P, Soares C, Hanan K, Parker D. The Joanna Briggs Institute Reviewers' Manual 2015: methodology for JBI scoping reviews. Adelaide: The Joanna Briggs Institute; 2015.

17. Arksey H, $\mathrm{O}^{\prime}$ Malley L. Scoping studies: towards a methodological framework. Int J Soc Res Methodol. 2005;8(1):19-32.

18. Cerniauskaite M, Quintas R, Boldt C, Raggi A, Cieza A, Bickenbach JE, et al. Systematic literature review on ICF from 2001 to 2009: its use, implementation and operationalisation. Disabil Rehabil. 2011;33(4):281-309.

19. Maribo T, Petersen KS, Handberg C, Melchiorsen H, Momsen AM, Nielsen CV, et al. Systematic literature review on ICF from 2001 to 2013 in the nordic countries focusing on clinical and rehabilitation context. J Clin Med Res. 2016;8(1):1-9.

20. Moher D, Liberati A, Tetzlaff J, Altman DG, PRISMA Group. Preferred reporting items for systematic reviews and meta-analyses: the PRISMA statement. Ann Intern Med. 2009;151(4):264-269.

21. Kloda LA, Bartlett JC. A characterization of clinical questions asked by rehabilitation therapists. J Med Libr Assoc. 2014;102(2):69-77.

22. Cieza A, Geyh S, Chatterji S, Kostanjsek N, Ustun B, Stucki G. ICF linking rules: an update based on lessons learned. J Rehabil Med. 2005;37(4):212-218. 
23. Berg B, Lune H. Chapter 11: an introduction to content analysis. Qualitative research methods for the social sciences. 8th ed. London: Pearson Education; 2012. pp. 349-382.

24. Hsieh HF, Shannon SE. Three approaches to qualitative content analysis. Qual Health Res. 2005;15(9):1277-1288.

25. Schreier M. Qualitative content analysis in practice. Los Angeles: SAGE; 2012.

26. Anner J, Schwegler U, Kunz R, Trezzini B, de Boer W. Evaluation of work disability and the international classification of functioning, disability and health: what to expect and what not. BMC Public Health. 2012;12(1):470.

27. Finger ME, Escorpizo R, Bostan C, De Bie R. Work rehabilitation questionnaire (WORQ): development and preliminary psychometric evidence of an ICF-based questionnaire for vocational rehabilitation. J Occup Rehabil. 2014;24(3):498-510.

28. Finger ME, Glassel A, Erhart P, Gradinger F, Klipstein A, Rivier $\mathrm{G}$, et al. Identification of relevant ICF categories in vocational rehabilitation: a cross sectional study evaluating the clinical perspective. J Occup Rehabil. 2011;21(2):156-166.

29. Finger ME, Selb M, De Bie R, Escorpizo R. Using the international classification of functioning, disability and health in physiotherapy in multidisciplinary vocational rehabilitation: a case study of low back pain. Physiother Res Int. 2014;20(4):231-241.

30. Glassel A, Rauch A, Selb M, Emmenegger K, Luckenkemper M, Escorpizo R. A case study on the application of international classification of functioning, disability and health (ICF)-based tools for vocational rehabilitation in spinal cord injury. Work 2012;41(4):465-474.

31. Glassel A, Finger ME, Cieza A, Treitler C, Coenen M, Escorpizo R. Vocational rehabilitation from the client's perspective using the international classification of functioning, disability and health (ICF) as a reference. J Occup Rehabil. 2011;21(2):167-178.

32. Escorpizo R, Finger ME, Glassel A, Cieza A. An international expert survey on functioning in vocational rehabilitation using the international classification of functioning, disability and health. $\mathbf{J}$ Occup Rehabil. 2011;21(2):147-155.

33. Escorpizo R, Gmunder HP, Stucki G. Introduction to special section: advancing the field of vocational rehabilitation with the international classification of functioning, disability and health (ICF). J Occup Rehabil. 2011;21(2):121-125.

34. Culler KH, Wang YC, Byers K, Trierweiler R. Barriers and facilitators of return to work for individuals with strokes: perspectives of the stroke survivor, vocational specialist, and employer. Top Stroke Rehabil. 2011;18(4):325-340.

35. Homa DB. Using the international classification of functioning, disability and health (ICF) in job placement. Work 2007;29(4):277-286.

36. Young AE. Employment maintenance and the factors that impact it after vocational rehabilitation and return to work. Disabil Rehabil. 2010;32(20):1621-1632.

37. Chow CM, Cichocki B, Croft B. The impact of job accommodations on employment outcomes among individuals with psychiatric disabilities. Psychiatr Serv. 2014;65(9):1126-1132.

38. Aiachini B, Cremascoli S, Escorpizo R, Pistarini C. Validation of the ICF core set for vocational rehabilitation from the perspective of patients with spinal cord injury using focus groups. Disabil Rehabil. 2016;38(4):337-345.

39. Conclave M, Fusaro G, Sala M, Martinuzzi A, Russo E, Frare M, et al. The ICF and labour policies project: the first italian nationwide experience of ICF implementation in the labour sector. Disabil Rehabil. 2009;31(Suppl 1):S16-S21.

40. Ferrario A, Verga FC, Piolatto PG, Pira E. Return to work after organ transplantation: a cross-sectional study on working ability evaluation and employment status. Transplant Proc. 2014;46(10):3273-3277.
41. Linden M, Baron S, Muschalla B. Relationship between workrelated attitudes, performance and capacities according to the ICF in patients with mental disorders. Psychopathology 2010;43(4):262-267.

42. Reichel C, Streit J, Wunsch S. Linking crohn's disease health status measurements with international classification of functioning, disability and health and vocational rehabilitation outcomes. J Rehabil Med. 2010;42(1):74-80.

43. Stergiou-Kita M, Grigorovich A. Guidelines for vocational evaluation following burns: integrated review of relevant process and factors. J Occup Rehabil. 2013;23(4):476-503.

44. Daniel K, Wolfe CD, Busch MA, McKevitt C. What are the social consequences of stroke for working-aged adults? A systematic review. Stroke 2009;40(6):e431-e440.

45. Martins AC. Using the international classification of functioning, disability and health (ICF) to address facilitators and barriers to participation at work. Work 2015;50(4):585-593.

46. Saltychev M, Kinnunen A, Laimi K. Vocational rehabilitation evaluation and the international classification of functioning, disability, and health (ICF). J Occup Rehabil. 2013;23(1):106-114.

47. Ptyushkin P, Vidmar G, Burger H, Marincek C, Escorpizo R. The international classification of functioning, disability and health (ICF) in vocational rehabilitation and disability assessment in slovenia: state of law and users' perspective. Disabil Rehabil. 2011;33(2):130-136.

48. Sevilla J, Sanford JA. A model of job activity description for workplace accommodation assessment. Assist Technol. 2013;25(2):117-124.

49. Zeilig G, Weingarden H, Shemesh Y, Herman A, Heim M, Zeweker M, et al. Functional and environmental factors affecting work status in individuals with longstanding poliomyelitis. J Spinal Cord Med. 2012;35(1):22-27.

50. Wang Y-, Lin Y-. Employment outcome predictors for people with disabilities in taiwan - a preliminary study using ICF conceptual frameworks. J Rehabil. 2013;79(2):3-14.

51. Escorpizo R, Stucki G. Disability evaluation, social security, and the international classification of functioning, disability and health: the time is now. J Occup Environ Med. 2013;55(6):644-651.

52. Escorpizo R, Cieza A, Beaton D, Boonen A. Content comparison of worker productivity questionnaires in arthritis and musculoskeletal conditions using the international classification of functioning, disability, and health framework. J Occup Rehabil. 2009;19(4):382-397.

53. Varekamp I, van Dijk FJ, Kroll LE. Workers with a chronic disease and work disability. problems and solutions. Bundesgesundheitsblatt Gesundheitsforschung Gesundheitsschutz. 2013;56(3):406-414.

54. Wasiak R, Young AE, Roessler RT, McPherson KM, van Poppel MN, Anema JR. Measuring return to work. J Occup Rehabil. 2007;17(4):766-781.

55. Abbott AD, Hedlund R, Tyni-Lenne R. Patients' experience postlumbar fusion regarding back problems, recovery and expectations in terms of the international classification of functioning, disability and health. Disabil Rehabil. 2011;33:(15-16):1399-1408.

56. Nilsing E, Soderberg E, Oberg B. Sickness certificates in sweden: did the new guidelines improve their quality? BMC Public Health. 2012;12(1):907.

57. Sturesson M, Bylund SH, Edlund C, Falkdal AH, Bernspang B. Quality in sickness certificates in a swedish social security system perspective. Scand J Public Health. 2015;43(8):841-847.

58. Andelic N, Johansen JB, Bautz-Holter E, Mengshoel AM, Bakke E, Roe C. Linking self-determined functional problems of patients with neck pain to the international classification of functioning, disability, and health (ICF). Patient Prefer Adherence. 2012;6:749-755. 
59. Aas RW, Grotle M. Clients using community occupational therapy services: sociodemographic factors and the occurrence of diseases and disabilities. Scand J Occup Ther. 2007;14(3):150-159.

60. Østerås N, Brage S, Garratt A, Benth JS, Natvig B, Gulbrandsen $P$. Functional ability in a population: normative survey data and reliability for the ICF based norwegian function assessment scale. BMC Public Health. 2007;7(1):278.

61. De Boer WE, Wind H, Van Dijk FJ, Willems HH. Interviews for the assessment of long-term incapacity for work: a study on adherence to protocols and principles. BMC Public Health. 2009;9(1):169.

62. Koolhaas W, van der Klink JJ, Vervoort JP, de Boer MR, Brouwer S, Groothoff JW. In-depth study of the workers' perspectives to enhance sustainable working life: comparison between workers with and without a chronic health condition. J Occup Rehabil. 2013;23(2):170-179.

63. van Velzen JM, van Bennekom CA, van Dormolen M, Sluiter JK, Frings-Dresen MH. Factors influencing return to work experienced by people with acquired brain injury: a qualitative research study. Disabil Rehabil. 2011;33(23-24):2237-2246.

64. Kuijer W, Brouwer S, Preuper HR, Groothoff JW, Geertzen JH, Dijkstra PU. Work status and chronic low back pain: exploring the international classification of functioning, disability and health. Disabil Rehabil. 2006;28(6):379-388.

65. Bakker RH, Bronsema J, Brouwer S, Dijkstra GJ, Haselager JJ, Groothoff JW. Disability insurance: can underwriting criteria for the self-employed be based on predictors used for disability amongst employees? J Insur Med. 2006;38(4):259-270.

66. Dalemans RJP, De Witte LP, Wade DT, Van den Heuvel WJA. A description of social participation in working-age persons with aphasia: a review of the literature. Aphasiology 2008;22(10):1071-1091.

67. Desiron HA, Donceel P, de Rijk A, Van Hoof E. A conceptualpractice model for occupational therapy to facilitate return to work in breast cancer patients. J Occup Rehabil. 2013;23(4):516-526.

68. Hoefsmit N, Houkes I, Nijhuis F. Environmental and personal factors that support early return-to-work: a qualitative study using the ICF as a framework. Work 2014;48(2):203-215.
69. Minis MA, Heerkens Y, Engels J, Oostendorp R, van Engelen B. Classification of employment factors according to the international classification of functioning, disability and health in patients with neuromuscular diseases: a systematic review. Disabil Rehabil. 2009;31(26):2150-2163.

70. Vooijs M, Leensen MC, Hoving JL, Daams JG, Wind H, FringsDresen MH. Disease-generic factors of work participation of workers with a chronic disease: a systematic review. Int Arch Occup Environ Health. 2015;88(8):1015-1029.

71. de Beer J, Engels J, Heerkens Y, van der Klink J. Factors influencing work participation of adults with developmental dyslexia: a systematic review. BMC Public Health. 2014;14:77.

72. Escorpizo R, Finger M, Reneman M. Integration and application of the international classification of functioning, disability and health (ICF). In: Schultz I, Gatchel RJ, editors. Handbook of return to work. From research to practice. New York: Springer; 2013.

73. Trenaman L, Miller WC, Queree M, Escorpizo R, SCIRE Research Team. Modifiable and non-modifiable factors associated with employment outcomes following spinal cord injury: a systematic review. J Spinal Cord Med. 2015;38(4):422-431.

74. Aas RW, Tuntland H, Holte KA, Roe C, Lund T, Marklund S, et al. Workplace interventions for neck pain in workers. Cochrane Database Syst Rev. 2011;2011(4):CD008160.

75. Escorpizo R, Graf S, Marti A, Noreau L, Post MW, Stucki G, et al. Domain sets and measurement instruments on participation and environmental factors in spinal cord injury research. Am J Phys Med Rehabil. 2011;90(11 Suppl 2):S66-S78.

76. Leyshon RT, Shaw LE. Using the ICF as a conceptual framework to guide ergonomic intervention in occupational rehabilitation. Work 2008;31(1):47-61.

77. Fayed N, Cieza A, Bickenbach JE. Linking health and healthrelated information to the ICF: a systematic review of the literature from 2001 to 2008. Disabil Rehabil. 2011;33(21-22):1941-1951.

78. Kaech Moll VM, Escorpizo R, Portmann Bergamaschi R, Finger ME. Validation of the comprehensive ICF core set for vocational rehabilitation from the perspective of physical therapists: an international delphi survey. Phys Ther. 2016;96(8):1262-1275. 